Review

\title{
Multifunctional Carbon Nanostructures for Advanced Energy Storage Applications
}

\author{
Yiran Wang ${ }^{1}$, Huige Wei ${ }^{1}$, Yang Lu ${ }^{2}$, Suying Wei ${ }^{3, *}$, Evan K. Wujcik ${ }^{2, *}$ and Zhanhu Guo ${ }^{1, *}$ \\ 1 Integrated Composites Laboratory (ICL), Department of Chemical \& Biomolecular Engineering, \\ University of Tennessee, Knoxville, TN 37976, USA; E-Mails: ywang160@utk.edu (Y.W.); \\ hwei@lamar.edu (H.W.) \\ 2 Materials Engineering and Nanosensor Laboratory (MEAN), Dan F. Smith Department of Chemical \\ Engineering, Lamar University, Beaumont, TX 77710, USA; E-Mail: ylu2@lamar.edu \\ 3 Department of Chemistry and Biochemistry, Lamar University, Beaumont, TX 77710, USA \\ * Authors to whom correspondence should be addressed; E-Mails: Suying.Wei@lamar.edu (S.W.); \\ Evan.Wujcik@lamar.edu (E.K.W.); zguo10@utk.edu (Z.G.); Tel.: +1-409-880-7976 (S.W.); \\ +1-409-880-8428 (E.K.W.); +1-865-974-2933 (Z.G.); Fax: +1-409-880-8270 (S.W.); \\ +1-409-880-2197 (E.K.W.); +1-865-974-7076 (Z.G.).
}

Academic Editor: Jiye Fang

Received: 9 April 2015 / Accepted: 5 May 2015 / Published: 8 May 2015

\begin{abstract}
Carbon nanostructures - including graphene, fullerenes, etc.- have found applications in a number of areas synergistically with a number of other materials. These multifunctional carbon nanostructures have recently attracted tremendous interest for energy storage applications due to their large aspect ratios, specific surface areas, and electrical conductivity. This succinct review aims to report on the recent advances in energy storage applications involving these multifunctional carbon nanostructures. The advanced design and testing of multifunctional carbon nanostructures for energy storage applicationsspecifically, electrochemical capacitors, lithium ion batteries, and fuel cells - are emphasized with comprehensive examples.
\end{abstract}

Keywords: multifunctional; nanocarbon; nanocomposite; nanomaterial; energy storage; capacitor; battery; fuel cell; graphene; CNT 


\section{Introduction}

Sustainable energy from renewable sources - such as wind, hydroelectric, geothermal, biological, nuclear, and solar - are in urgent demand due to the ever increasing energy crisis arising from the limited reserves of fossil fuels [1-4]. Given the intermittent nature of these renewable energy resources, reliable energy storage systems are critically needed to store and supply energy in a stable manner. Electrochemical energy storage systems (EESS) - including electrochemical capacitors (ECs), batteries, and fuel cellsjoin various existing energy storage systems such as pumped hydro storage, thermal energy storage, compressed air energy storage, and flywheel energy storage [5,6]. Carbon nanostructures and their multifunctional composites have attracted significant research interest for EESS applications due to their large specific surface area and excellent electrical conductivities [7-11].

Carbon nanomaterials including Buckminster fullerenes [12-14], carbon nanotubes (CNTs) [15-19], and graphene [20-24] have attracted much attention in the last three decades. Their outstanding thermal [25,26], electrical [27-30], optical [31-33], and mechanical [26,34] properties, as well as large aspect ratios and higher specific surface areas $[35,36]$, are promising for applications including sensors [37-44], photovoltaics [45-47], field emission transistors [48-50], fuel cells [51-53], supercapacitors [54-57], composites [58-62], biomaterials [63,64], and environment remediation [65,66], among others. On the nanoscale, the physical and chemical behaviors of the nanomaterials are strongly determined by their structure and interfacial interactions with their surrounding bulk materials. Each type of carbon materials has its own pros and cons. For example, CNTs is a good choice to increase the energy density of ECs considering their unique tubular porous structure and superior electrical properties. However, the high production costs largely limit more widespread applications [67]. Graphene, as a 2D carbon nanostructure, has the advantages of high surface area and high conductivity but it is easy to get restacked during the preparation [61]. Three-dimensional hierarchical carbon materials like activated carbon and templated carbon are highlighted due to their high surface area and rich pore structures. However, the specific capacitance is largely limited at high current density due to the presence of micropores and relative low conductivity [68]. Onion-like carbon can be fully accessible to ions, resulting in excellent performance but limited capacitance $\left(\sim 30 \mathrm{~F} \cdot \mathrm{g}^{-1}\right)$ [69]. Due to recent developments in the synthesis and manipulation of carbon nanomaterials-including controlled synthesis [70-72], functionalization [73,74], and self-assembly [75,76] techniques - and their multifunctional composites, energy storage performances have appreciably increased [77-80]. Previous reviews regarding these multifunctional carbon nanostructures (MCNs) have been published elsewhere [81-85]; however, very few are focused on recent energy storage applications. Herein, the progress of the many recent advances in energy applications involving MCNs will be discussed. This shall be approached with an emphasis on energy storage applications in three distinct areas: electrochemical capacitors, lithium ion batteries (LIBs), and fuel cells.

\section{MCNs for Electrochemical Capacitors}

ECs have been found to be promising for bridging batteries (high energy density but relatively low power density) and conventional capacitors (high power density but low energy density) with their relatively high both power and energy densities, exceptional long cycling life, and reliability [86,87]. 
Carbon nanostructures including activated carbons (ACs), carbon nanotubes (CNTs), carbon nanofibers (CNFs), carbon onions, and graphene have been utilized to fabricate electric double layer capacitors (EDLC) due to their high specific surface area and high electrical conductivity [88-90]. The energy is stored via the physical adsorption/desorption of ions at the electrode/electrolyte interface, which is a non-Faradic process where no oxidation/reduction reactions are involved. The energy storage mechanism allows a fast charge/discharge rate, i.e., high power density $\left(>10 \mathrm{~kW} \cdot \mathrm{kg}^{-1}\right)$ and superb cycling stability ( $>10^{6}$ cycles). However, their energy density is still lower than those of pseudocapacitors where charges are stored or released through the redox reactions occurring at or near the surface of the electrode material [91,92].

To increase the energy densities of carbon nanostructures, different strategies have been explored, i.e., to increase the effective utilization of the specific surface area or to introduce pseudocapacitance to the electrode material [93]. For example, considerable research interest has been focused on the full utilization of the surface area of graphene. These materials have been proposed as the next generation of electrode materials for EDLCs due to their high surface area (a theoretical value of $2630 \mathrm{~m}^{2} \cdot \mathrm{g}^{-1}$ ), sufficient porosity, superior electrical conductivity, broad potential window, and rich surface chemistry [56]. The oxidation and subsequent reduction of graphene oxide (GO) has proved to be the most effective method in the mass production of graphene for industrial applications [94,95]. Unfortunately, reduced GO is prone to agglomeration due to the strong van der Waals interactions between graphene sheets, which ultimately results in unsatisfactory supercapacitive performances [96]. Combining graphene with other carbon nanomaterials such as CNTs has been explored. As illustrated in Figure 1, CNTs were grown in between the graphene sheets and distributed uniformly, but sparsely, on the entirety of the sheets' surface to form 3D CNT/graphene sandwich structures [97,98]. Herein, CNTs function as "spacers" to stabilize the graphene from aggregation so that the entire graphene surface can be accessed by electrolyte ions.
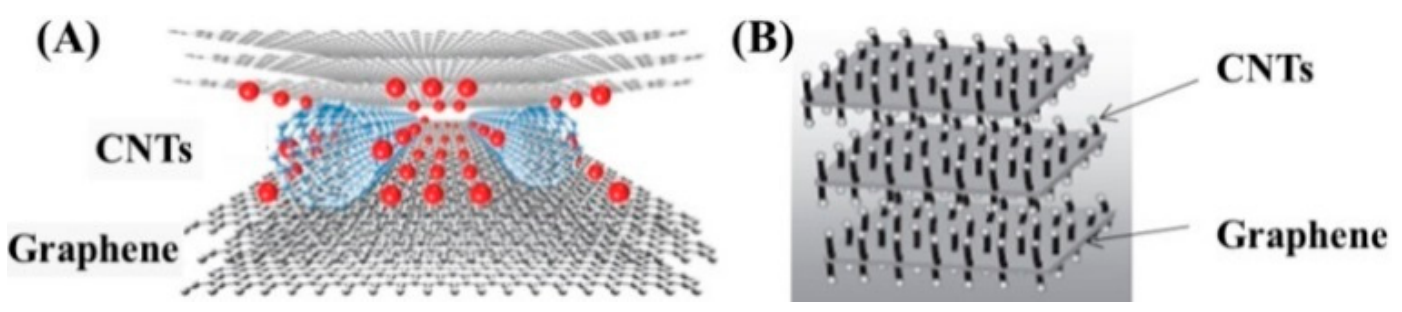

Figure 1. Two models of the 3D CNTs/graphene sandwich structures, where CNTs serve as a spacer to stabilize graphene sheets from agglomeration. Adapted from [97] with permission from the PCCP Owner Societies and from [98] with permission from John Wiley and Sons, 2010.

Yang et al. [99] designed a simple route to enhance the utilization of graphene nanosheets (GS) and to improve the capacitive performances through combining 1D CNTs and 2D GS. The effects of the microstructure and capacitive performance of the GS-CNT composites are systematically investigated by varying the weight ratio of reduced graphene oxide ( $\mathrm{rGO}$ ) to MWNTs. Figure 2a shows the FE-SEM image of GS-CNTs-9-1 (where the weight feed ratio of GO to MWNTs is 9:1), which exhibits a more crumpled and rougher surface compared to other GS-CNTs. The stacking of GS is largely inhibited due to the inset of small amounts of MWCNTs. Yet excess MWNTs gave rise to typical MWNTs morphology and GS agglomerates. The GS-CNTs-9-1 also possesses the largest enclosed CV area at a 
scan rate of $20 \mathrm{mV} \mathrm{s}^{-1}$ (Figure $2 \mathrm{~b}$ ), indicating the highest energy storage capability. The corresponding calculated specific capacitance is $326.5 \mathrm{~F} / \mathrm{g}$, much higher than the GS-CNTs with other weight ratios (Figure 2c), suggesting the most effective utilization of GS in the composites. In the Ragone plot (Figure 2d), the GS-CNTs-9-1 is observed to deliver an energy density of $45.3 \mathrm{Wh} \cdot \mathrm{kg}^{-1}$ with a power density of $3.3 \mathrm{~kW} \cdot \mathrm{kg}^{-1}$ at a long current drain time $(50 \mathrm{~s})$ in a three-electrode setup, much higher than that of $\mathrm{rGO}\left(11.5 \mathrm{Wh} \cdot \mathrm{kg}^{-1}\right.$ and $\left.0.8 \mathrm{~kW} \cdot \mathrm{kg}^{-1}\right)$. This shows the promise of the 3D hierarchical GS-CNTs nanocomposites for high-power EC applications with high energy densities.
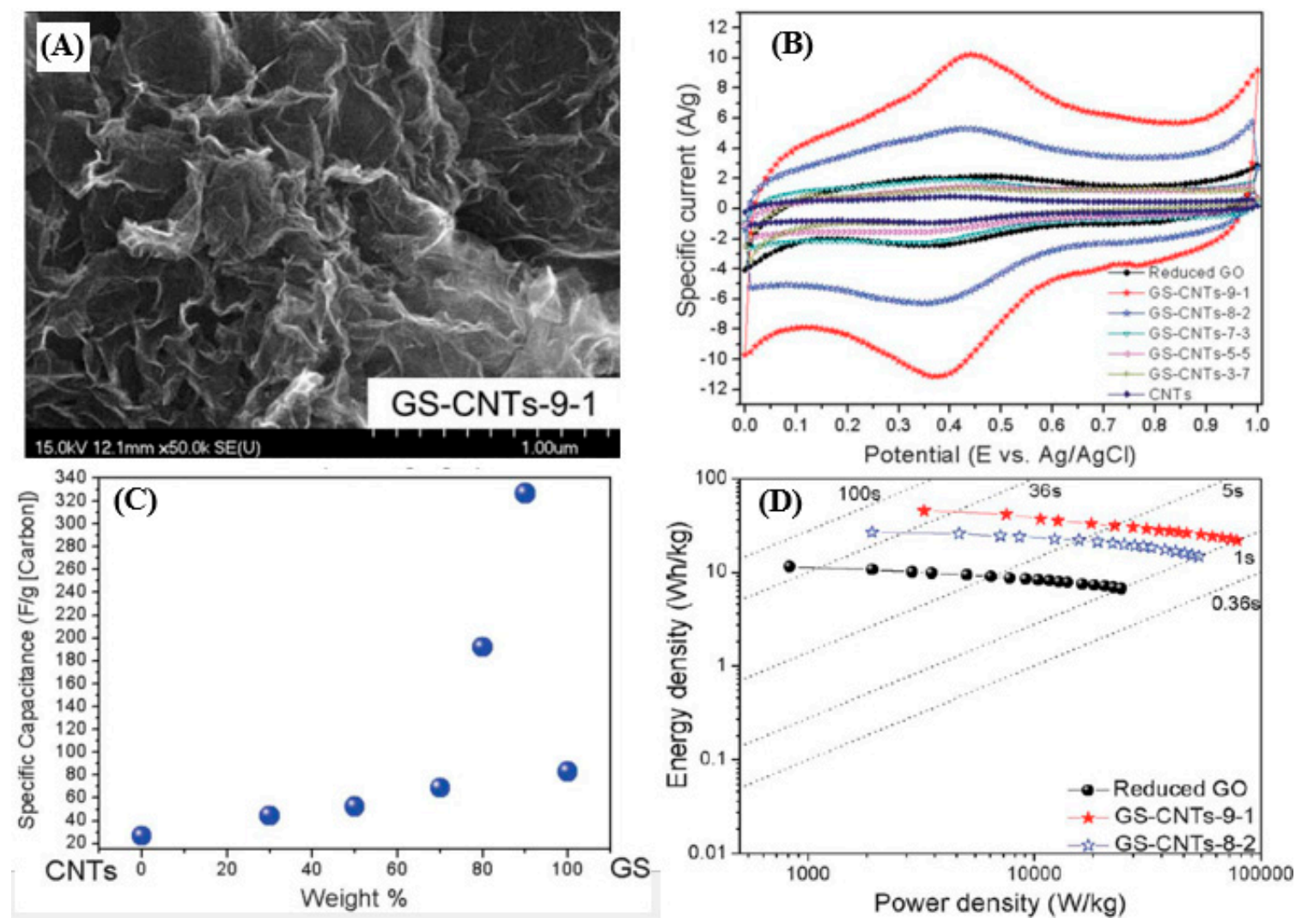

Figure 2. (A) FE-SEM image of GS-CNTs-9-1 (where the weight feed ratio of GO to MWNTs is 9:1). (B) CV curves measured at $20 \mathrm{mV} \cdot \mathrm{s}^{-1}$ in $0.5 \mathrm{M} \mathrm{H}_{2} \mathrm{SO}_{4}$ for GS-CNTs nanocomposites with various weight ratios of reduced GO to MWNTs. (C) The dependence of $C s$ on the composition for GS-CNTs nanocomposites. (D) A plot of energy density against power density for reduced GO and GS-CNTs nanocomposites. Reproduced from [99] with permission from the Royal Society of Chemistry, 2011.

Another effective strategy to enhance the energy density of carbon nanostructure-based ECs is to introduce pseudocapacitance to the EDLCs. Two approaches have been developed. The first one is to introduce heteroatoms into the carbon frameworks [100,101]. Certain nitrogen doping approaches appear to be the most promising methods so far, while maintaining superb cycling stability [102]. Chen et al. [103] reported a facile route to prepare high-content nitrogen-doped porous CNFs containing graphitic frameworks by using macroscopic-scale CNFs as the precursor. Polypyrrole (PPy) was polymerized onto CNFs followed by carbonization at different temperatures $\left(500,700,900\right.$, and $\left.1100{ }^{\circ} \mathrm{C}\right)$ in an $\mathrm{N}_{2}$ atmosphere to obtain a high content of nitrogen doping in CNTs. The X-ray photoelectron spectroscopy (XPS) and $\mathrm{N}_{2}$ adsorption measurements reveal that the nitrogen-doped CNFs annealed at 
$900{ }^{\circ} \mathrm{C}$ (N-CNFs-900) demonstrated localized graphitic structure and more favorable morphologies featured with a larger specific surface area and interconnected pores. The high-resolution TEM (HRTEM) image of the N-CNFs-900 is shown in Figure 3a. As theorized, the N-CNFs-900 displays higher specific capacitances at varying charge/discharge current densities than its counterparts in a three-electrode configuration, Figure $3 \mathrm{~b}$. An excellent rate capability of $81.72 \%$ is also obtained at higher current densities $\left(>1 \mathrm{~A} \cdot \mathrm{g}^{-1}\right)$. The Nyquist impedance spectrum, Figure 3c, further discloses a smaller semicircle, characteristic of a lower charge transfer resistance, in the high frequency region in the N-CNFs-900 electrode. The equivalent serial resistance (ESR) for the N-CNFs-900 is very low, about $0.14 \Omega$, compared to $1.25 \Omega$ for the CNFs@Ppy and $0.92 \Omega$ for the CNFs-900. The lower ESR is crucial for achieving higher rate capability and power density for the electrochemical capacitors. A good cycling stability is also obtained in the N-CNFs-900 electrode by retaining above $97 \%$ of the initial capacitance after 3000 cycles (Figure 3d).

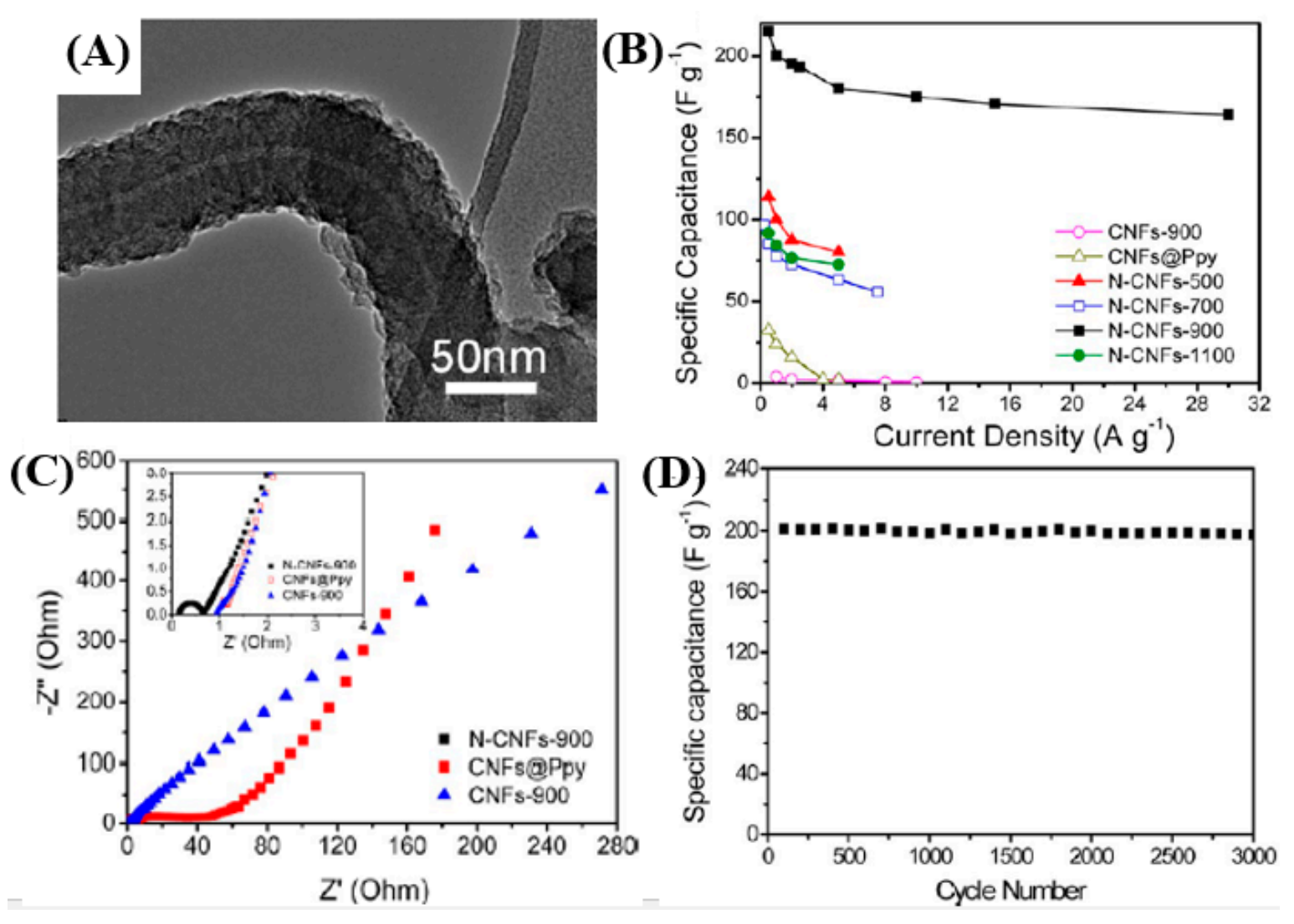

Figure 3. (A) TEM images of N-doped CNFs annealing at $900{ }^{\circ} \mathrm{C}$. (B) Specific capacitances of CNFs-900, CNFs@Ppy, N-CNFs-500, N-CNFs-700, N-CNFs-900, and N-CNFs-1100 at varying current densities. (C) Electrochemical impedance spectra (inset: magnified $0-4 \Omega$ region) under the influence of an $\mathrm{AC}$ voltage of $5 \mathrm{mV}$. (D) Cycling performance of the N-CNFs-900 as gravimetric capacitance calculated from the discharge curves of 3000 cycles. Reproduced from [103] with permission from American Chemical Society, 2012.

The second approach to introduce pseudocapacitance into carbon is to fabricate carbon-based pseudocapacitive composites [67,104]. For example, transition metal oxides, intrinsically conductive polymers including polyaniline (PANI) [105-108], polypyrrole (PPy) [109,110], and polythiophene or 
their derivatives [111] are commonly used as pseudocapacitive electrode materials with high specific capacitances due to their rich redox reactions. Cheng et al. [112] fabricated graphene/ $\mathrm{MnO}_{2}$ composite electrodes by in situ anodic electrodeposition of $\mathrm{MnO}_{2}$ on the graphene electrode (apparent electrode surface area is $2 \mathrm{~cm}^{2}$ ). The electrochemical properties of the pristine graphene and the composites were examined in $1 \mathrm{M} \mathrm{KCl}$ using a two-electrode configuration. Figure 4a depicts the SEM image of the graphene, which exhibits wrinkled-paper-like morphologies. The pure graphene paper shows an enhanced capacitance under $4 \mathrm{~mA}$ charge/discharge rate for 1300 cycles (Figure 4b). The long time charging and discharging may help the ions to fully access to the graphene surface area, as confirmed by the increased capacitance. A $60 \%$ increase in the capacitance is observed in Figure 4c, further confirming the positive role of the electro-activation process, which is probably due to the movement of GS in order to adjust to the different electrolyte ions. The morphology of the graphene coated with $\mathrm{MnO}_{2}$ flowers is shown in Figure 4d. The $\mathrm{MnO}_{2}$ nanoflowers are composed of many tiny nanorods (the inset of Figure 4d). The retention ratio in Figure 4e remains almost constant in the first 150 cycles, and only dropped by $1 \%$ after 1300 cycles, indicating an excellent cycling stability of the $\mathrm{MnO}_{2}$-coated graphene. The charging and discharging curves under $1 \mathrm{~mA}$ of the electrode before and after $\mathrm{MnO}_{2}$ coating are shown in Figure 4f. The discharge time becomes longer and the corresponding calculated specific capacitance increases from 245 to $328 \mathrm{~F} / \mathrm{g}$ after the $\mathrm{MnO}_{2}$ coating. Correspondingly, the energy density increases from 8.5 to $11.4 \mathrm{Wh} \cdot \mathrm{kg}^{-1}$.
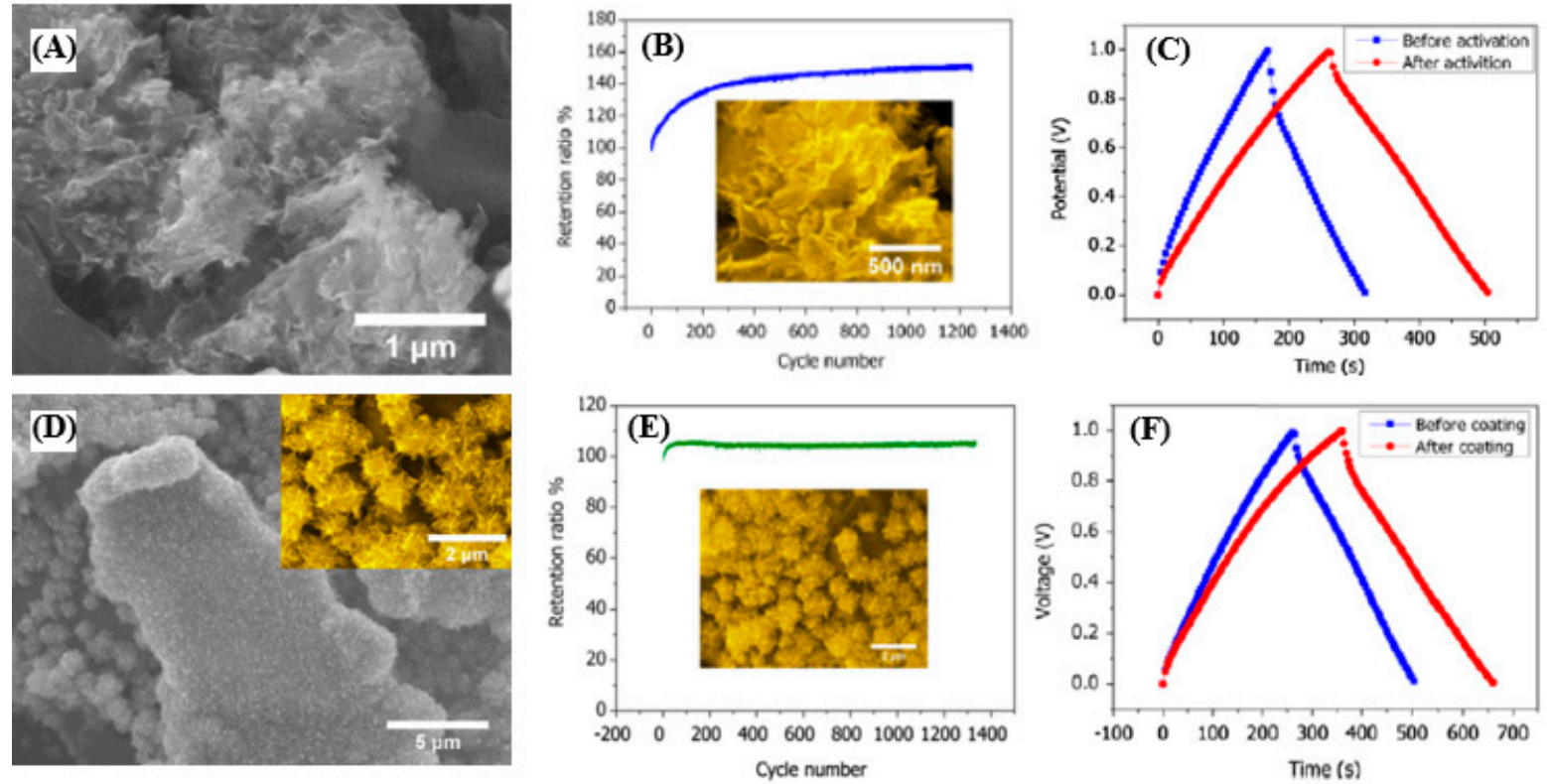

Figure 4. (A) SEM image of grapheme. (B) Electro-activation of graphene electrode; the SEM image below the curve shows the morphology of the graphene after activation. (C) Comparison of charge and discharge curves before and after electro-activation. (D) SEM image of $\mathrm{MnO}_{2}$-coated grapheme; the inset is a part of the image highlighting the $\mathrm{MnO}_{2}$ nanostructures. (E) Capacitance retention of graphene electrode after $\mathrm{MnO}_{2}$ coating; the image below the retention curve shows the SEM morphology after cycling. (F) Comparison of charge and discharge curves before and after $\mathrm{MnO}_{2}$ coating. Reproduced from [112] with permission from Elsevier, 2011. 
However, even though an enhanced capacitance and energy density have been achieved after the introduction of metal oxides to the carbon nanostructures, there are still concerns about the poor electrical conductivity of the metal oxide coating [113]. Decreased supercapacitive performances are expected in practical applications where high mass loading of the electrode materials are densely packed to achieve the desired capacitance and energy storage. To address this problem, Yu et al. [114] have developed a "three dimensional (3D) conductive wrapping" method to rationally design ternary systems. Using graphene as a model carbon material, they have prepared graphene/ $\mathrm{MnO}_{2} / \mathrm{CNT}$ (GMC) and graphene/ $\mathrm{MnO}_{2} /$ poly(3,4-ethylenedioxythiophene) poly-(styrenesulfonate) (PEDOT:PSS) (GMP) composites for the high-performance electrochemical electrodes (Figure 5).
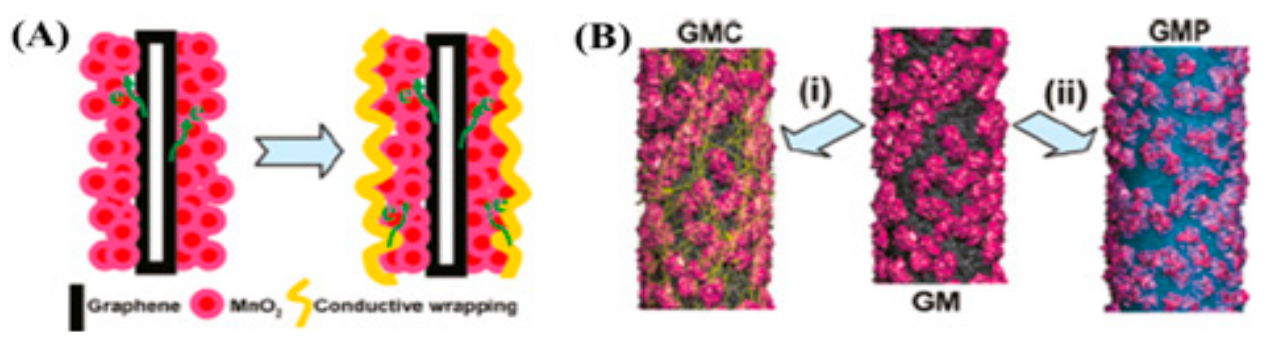

Figure 5. (A) Schematic illustration showing conductive wrapping of graphene/ $\mathrm{MnO}_{2}$ (GM) to introduce an additional electron transport path (in a discharge cycle). (B) Models of graphene/ $\mathrm{MnO}_{2} / \mathrm{CNT}$ (GMC) and graphene/ $\mathrm{MnO}_{2} /$ conducting polymer (GMP) systems formed by wrapping of GM nanostructures with CNTs or conducting polymers. Reproduced from [114] with permission from the American Chemical Society, 2011.

Besides the graphene layer underneath the $\mathrm{MnO}_{2}$, the ultrathin layer of SWNTs or conducting polymer that wraps around graphene/ $\mathrm{MnO}_{2}(\mathrm{GM})$ three-dimensionally can also provide an additional electron transport path. Simultaneously, the SWNTs and polymer are actively participated in the charge storage process since both can contribute to the whole capacitance via electric double layer capacitance or pseudocapacitance. As expected, GMP and GMC exhibit superior performances in terms of capacitance performance and rate performance in comparison with GM. Although the GMP system offers higher specific capacitance than the GMC, due to large pseudocapacitance contributed from the conductive polymer, the wrapping with CNTs can be advantageous in those applications that require high operation voltages owing to their better electrochemical stability across a large voltage range and environmental safety.

The combination of different carbon materials renders a greatly enhanced surface area and improved chemical stability, thus favoring the EC performance. Furthermore, the introduction of pseudocapacitive heteroatoms and organic materials also offers a good way forward to design multifunctional carbon nanostructures with high stability, excellent functionality, and moderate cost, which are prerequisites for scaleable ECs.

\section{MCNs for Lithium Ion Batteries}

Carbon-based rechargeable batteries have gained extensive attention, particularly after the commercialization of the Li-ion battery (LIB) from Sony laboratories. Here, the metallic lithium is replaced by a carbon host structure, which can reversibly absorb/desorb lithium ions at low 
electrochemical potentials [115-118]. Yet, there are disadvantages associated with carbon-based anode materials - for example, low theoretical specific capacity $\left(372 \mathrm{mAh} \cdot \mathrm{g}^{-1}\right.$ for graphite [119]) and low rate capability.

To improve their performances, considerable efforts have been focused on surface modification by chemical doping [120]. Chemical dopants such as phosphorus, boron, and nitrogen have been reported to enhance the Li-ion storage capability originating from the enhanced reactivity and electric conductivity. For example, Reddy et al. [121] demonstrated a controlled growth of nitrogen-doped graphene layers by liquid precursor-based chemical vapor deposition (CVD) technique and evaluated its applications for LIBs. Figure 6a shows the high-resolution TEM (HRTEM) micrograph of the three-layered N-doped grapheme, where both amorphous carbon and crystalline graphene were observed. Figure $6 \mathrm{~b}$ shows the voltage versus specific capacity plots conducted at $5 \mu \mathrm{A} \cdot \mathrm{cm}^{-2}$ between 3.2 and $0.02 \mathrm{~V} v s \mathrm{Li} / \mathrm{Li}^{+}$in $1 \mathrm{M}$ LiPF6 in a 1:1 (v/v) mixture of ethylene carbonate (EC) and dimethyl carbonate (DMC). The first cycle shows a discharge capacity of around $0.25 \mathrm{mAh} \cdot \mathrm{cm}^{-2}$ and a loss in the capacity is observed in the second cycle due to the solid electrolyte interface (SEI) formation. Figure 6c shows the rate capability study of the N-doped graphene electrode. Even operated at very high current rates, i.e., $100 \mu \mathrm{A} \cdot \mathrm{cm}^{-2}$, excellent capacity retention of $60 \%$ of the nominal capacity was observed, indicating that the N-doped graphene electrode could be used as an excellent high rate electrode for LIB. A comparison of the cycling stability is also conducted at $5 \mu \mathrm{A} \cdot \mathrm{cm}^{-2}$ between 3.2 and $0.02 \mathrm{~V} v s . \mathrm{Li} / \mathrm{Li}^{+}$as shown in Figure $6 \mathrm{~d}$. The N-doped graphene shows higher discharge capacity $\left(0.05 \mathrm{mAh} \cdot \mathrm{cm}^{-2}\right)$ than that of pristine graphene $\left(0.03 \mathrm{mAh} \cdot \mathrm{cm}^{-2}\right)$ and remains stable over 50 cycles. The increase in the reversible discharge capacity of the $\mathrm{N}$-doped graphene over pristine graphene can be attributed to the topological defects induced in the $\mathrm{N}$-doped graphene electrode. First, a large number of surface defects are induced onto the graphene films by N-doping, which leads to the formation of a disordered carbon structure that further enhanced the $\mathrm{Li}^{+}$ intercalation abilities. The $\mathrm{N}$-doped graphene also has a high percentage of pyridinic $\mathrm{N}$ atoms, which could also be involved in the improved reversible capacity of the N-doped graphene electrode compared to that of the pristine graphene electrode.
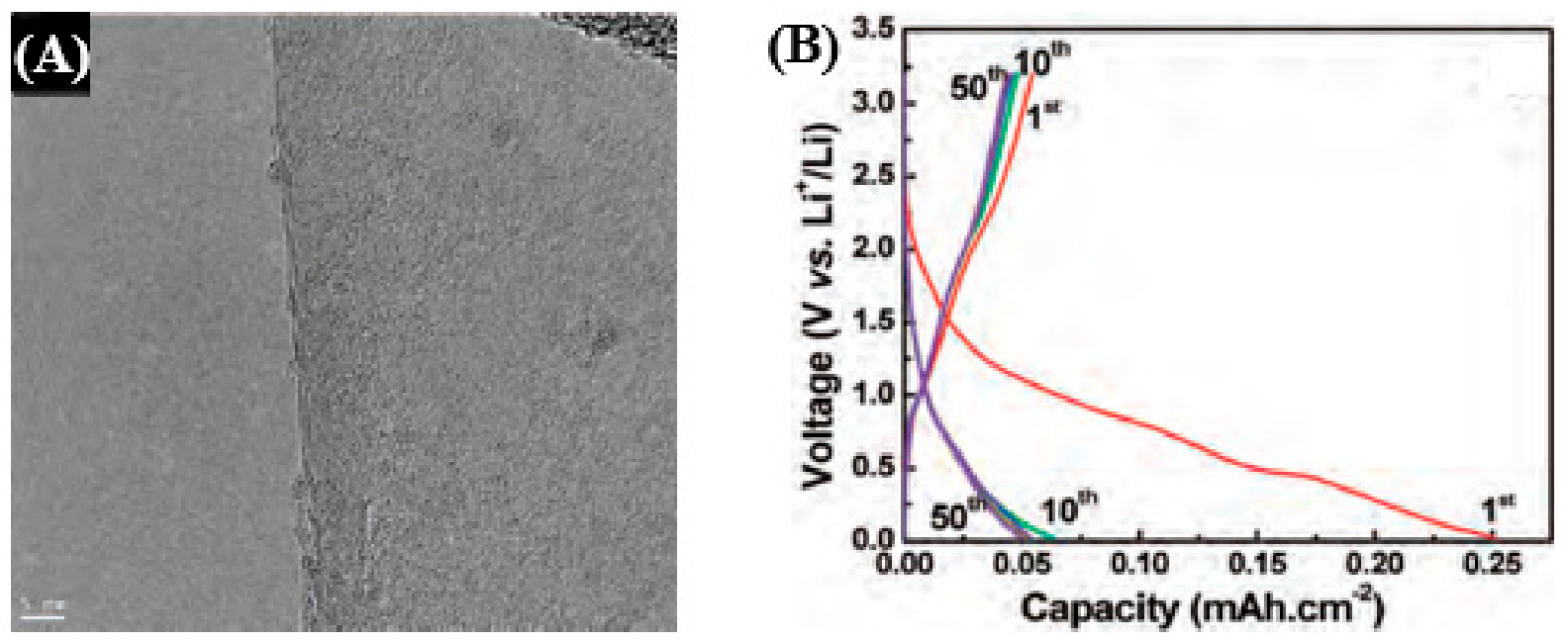

Figure 6. Cont. 

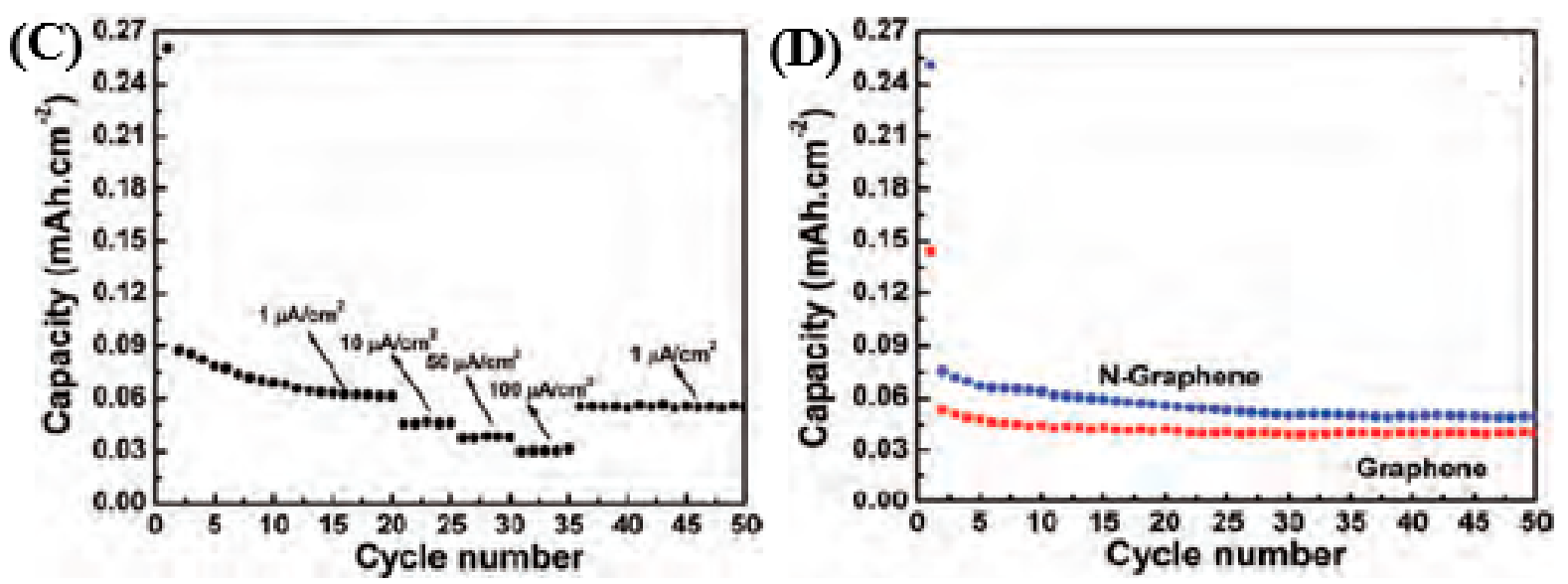

Figure 6. (A) HRTEM image of three-layered N-doped grapheme. (B) Charge-discharge voltage profiles for the $\mathrm{N}$-doped graphene electrode cycled at a rate of $5 \mu \mathrm{A} \cdot \mathrm{cm}^{-2}$ between 3.2 and $0.02 \mathrm{~V} v s . \mathrm{Li} / \mathrm{Li}^{+}$. (C) Rate capability studies of $\mathrm{N}$-doped graphene films: discharge capacity $v$ s. cycle number at various current rates $\left(1,10,50\right.$, and $\left.100 \mu \mathrm{A} \cdot \mathrm{cm}^{-2}\right)$. (D) Cycling stability for the pristine graphene and $\mathrm{N}$-doped graphene cycled at a rate of $5 \mu \mathrm{A} \cdot \mathrm{cm}^{-2}$ between 3.2 and $0.02 \mathrm{~V} v s . \mathrm{Li} / \mathrm{Li}^{+}$. Reproduced from [121] with permission from the American Chemical Society, 2010.

The doping effect on other carbon nanostructure as anodes for LIB has also been studied using porous carbon nanofiber webs (CNFWs). For example, Qie et al. [53] reported a facile strategy to synthesize CNFWs using a PPy precursor synthesized via a modified oxidative template assembly route, followed by carbonization-activation with $\mathrm{KOH}$.

Figure 7a shows a HRTEM micrograph of the CNFWs. Large quantities of micropores are uniformly distributed within the CNFWs. The uniform micropores are inferred to result from the combustion of PPy precursors during the pyrolysis process. Figure $7 \mathrm{~b}$ shows the charge/discharge profiles of the CNFWs during the initial three cycles at a current density of $0.1 \mathrm{~A} \cdot \mathrm{g}^{-1}$. The initial reversible capacity can reach as high as $1280 \mathrm{mAh} \cdot \mathrm{g}^{-1}$, more than three times higher than the theoretical value of graphite $\left(372 \mathrm{mAh} \cdot \mathrm{g}^{-1}\right)$. The CNFWs' anode also displays excellent cycling performance with high capacities (Figure 7c). The reversible capacity is $633 \mathrm{mAh} \cdot \mathrm{g}^{-1}$ in the first cycle and then gradually increases to $943 \mathrm{mAh} \cdot \mathrm{g}^{-1}$ after 600 cycles. The increase in the capacity with the cycling can be attributed to the activation of the porous anode. Such an exceptionally high $\mathrm{Li}^{+}$ion storage capacity is claimed to be first witnessed in a carbon-based anode material. It is worth noting that the CNFWs anode still shows high $\mathrm{Li}^{+}$ion storage and excellent cycling stability even at very high rates (Figure 7d). For testing, the cell was first discharged/charged at a current density of $0.1 \mathrm{~A} \cdot \mathrm{g}^{-1}$ for 10 cycles, and then at various current densities ranging from 0.5 to $20 \mathrm{~A} \cdot \mathrm{g}^{-1}$ each for 20 cycles. The reversible capacities are 924, 773, 637, 505 , and $321 \mathrm{mAh} \cdot \mathrm{g}^{-1}$ at $0.5,1,2,5$, and $10 \mathrm{~A} \cdot \mathrm{g}^{-1}$, respectively. Even at an extremely high current density of $20 \mathrm{~A} \cdot \mathrm{g}^{-1}$ ( $\sim 40 \mathrm{~s}$ to full charge), the reversible capacity is $226 \mathrm{mAh} \cdot \mathrm{g}^{-1}$, which is about $60 \%$ of the theoretical capacity of graphite. When the rate is switched back to $0.1 \mathrm{~A} \mathrm{~g}^{-1}$ after cycling at different rates, the specific capacity can be recovered to $1321 \mathrm{mAh} \cdot \mathrm{g}^{-1}$, indicating an excellent cycling performance. Apart from the carbon-based anodes, the transitional metal oxides including $\mathrm{Co}_{3} \mathrm{O}_{4}, \mathrm{MoO}_{3}$, and $\mathrm{Fe}_{3} \mathrm{O}_{4}$ are another important type of anode material for LIB [122-124]. These transitional metal 
oxides can react with $6 \mathrm{Li}^{+}$per formula unit, giving rise to a significantly larger reversible capacity than that of commercial graphite. However, large volume expansion/contraction during the $\mathrm{Li}^{+}$ insertion/extraction and serious particle aggregation leading to a serious loss of capacity with cycling and a poor cycling stability [125]. Meanwhile, carbon-based anode materials, especially graphene, are known for their large initial discharge capacity and high reversible capacity [126]. Therefore, the combination of nanostructures with transitional metal oxides to achieve desirable electrochemical performance has proved to be an effective strategy $[127,128]$.
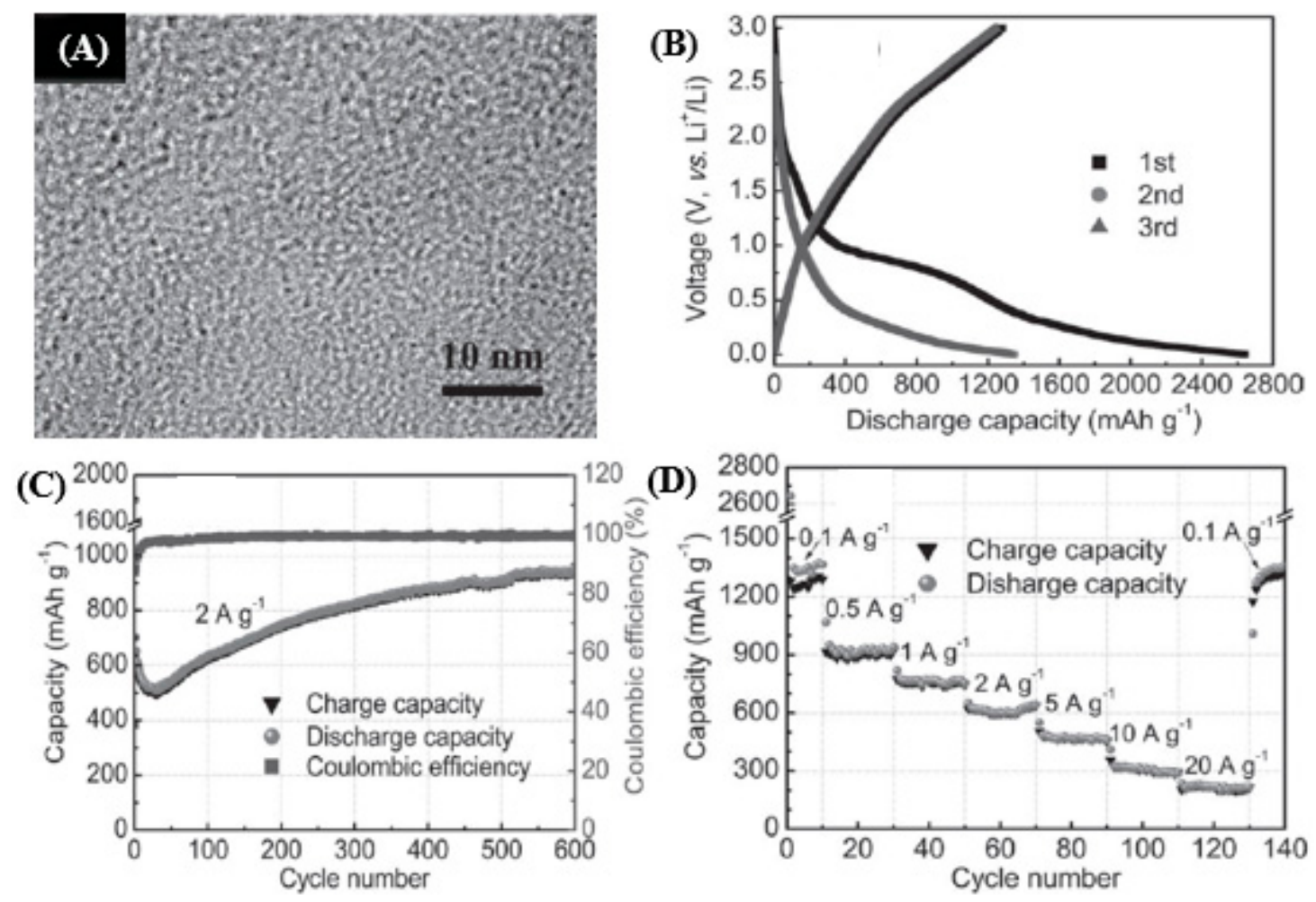

Figure 7. (A) HRTEM of carbon nanofiber webs (CNFWs) doped with nitrogen. (B) Charge/discharge curves at $0.1 \mathrm{~A} / \mathrm{g}$. (C) Cyclability and Coulombic efficiency at $2 \mathrm{~A} / \mathrm{g}$; and (D) capacity over cycling at different rates. Reproduced from [53] with permission from John Wiley and Sons, 2012.

The reduced graphene oxide $(\mathrm{rGO}) / \mathrm{Fe}_{2} \mathrm{O}_{3}$ composites for LIB anode materials were reported by Zhu et al. [129], employing a facile two-step synthesis method. Figure 8a presents an SEM image of the $\mathrm{rGO} / \mathrm{Fe}_{2} \mathrm{O}_{3}$ composite. The $\mathrm{Fe}_{2} \mathrm{O}_{3} \mathrm{NPs}$ are observed to be uniformly distributed on the surface of $\mathrm{rGO}$, confirming the successful synthesis of $\mathrm{rGO} / \mathrm{Fe}_{2} \mathrm{O}_{3}$ composites. The $\mathrm{rGO} / \mathrm{Fe}_{2} \mathrm{O}_{3}$ composites exhibit two

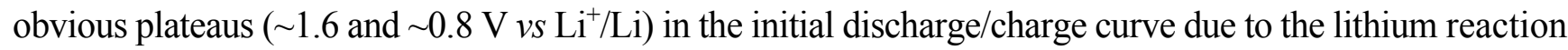
with $\mathrm{Fe}_{2} \mathrm{O}_{3}$ nanoparticles (Figure 8b). The discharge and charge capacities are 1693 and $1227 \mathrm{mAh} \cdot \mathrm{g}^{-1}$, respectively, based on the mass of $\mathrm{Fe}_{2} \mathrm{O}_{3}$. An excellent rate performance is also accomplished in $\mathrm{rGO} / \mathrm{Fe}_{2} \mathrm{O}_{3}$ composites, which can reach as high as $\sim 800 \mathrm{mAh} \cdot \mathrm{g}^{-1}$ even at a current density of $800 \mathrm{~mA} \cdot \mathrm{g}^{-1}$ (Figure 8c). Figure $8 \mathrm{~d}$ shows the cycling performance of the $\mathrm{rGO} / \mathrm{Fe}_{2} \mathrm{O}_{3}$ composites at $100 \mathrm{mAh} \cdot \mathrm{g}^{-1}$ in the range between 3.0 and $0.005 \mathrm{~V}$. The superior capacity and good capacity retention observed in the $\mathrm{rGO} / \mathrm{Fe}_{2} \mathrm{O}_{3}$ composites are explained by the $\mathrm{Fe}_{2} \mathrm{O}_{3}$ nanoparticles anchored on the surface of the rGO templates, which behave as spacers and greatly facilitate the lithium insertion/extraction. 
In summary, porous nanostructures can not only shorten the transport length for $\mathrm{Li}^{+}$but also offer a large electrode/electrolyte interface for the charge-transfer reaction. Chemical dopants in carbon materials such as phosphorus, boron, and nitrogen can modify the carbon structure, thus contributing to a substantial increase in specific capacity relative to pure carbon due to the enhanced reactivity, electric conductivity, and $\mathrm{Li}^{+}$-ion storage capacity. Incorporating metal oxides in carbon nanostructures is also another alternative owing to the high theoretical capacity and capability of intake excess of $\mathrm{Li}^{+}$ions of metal oxides during the charge-discharge process.
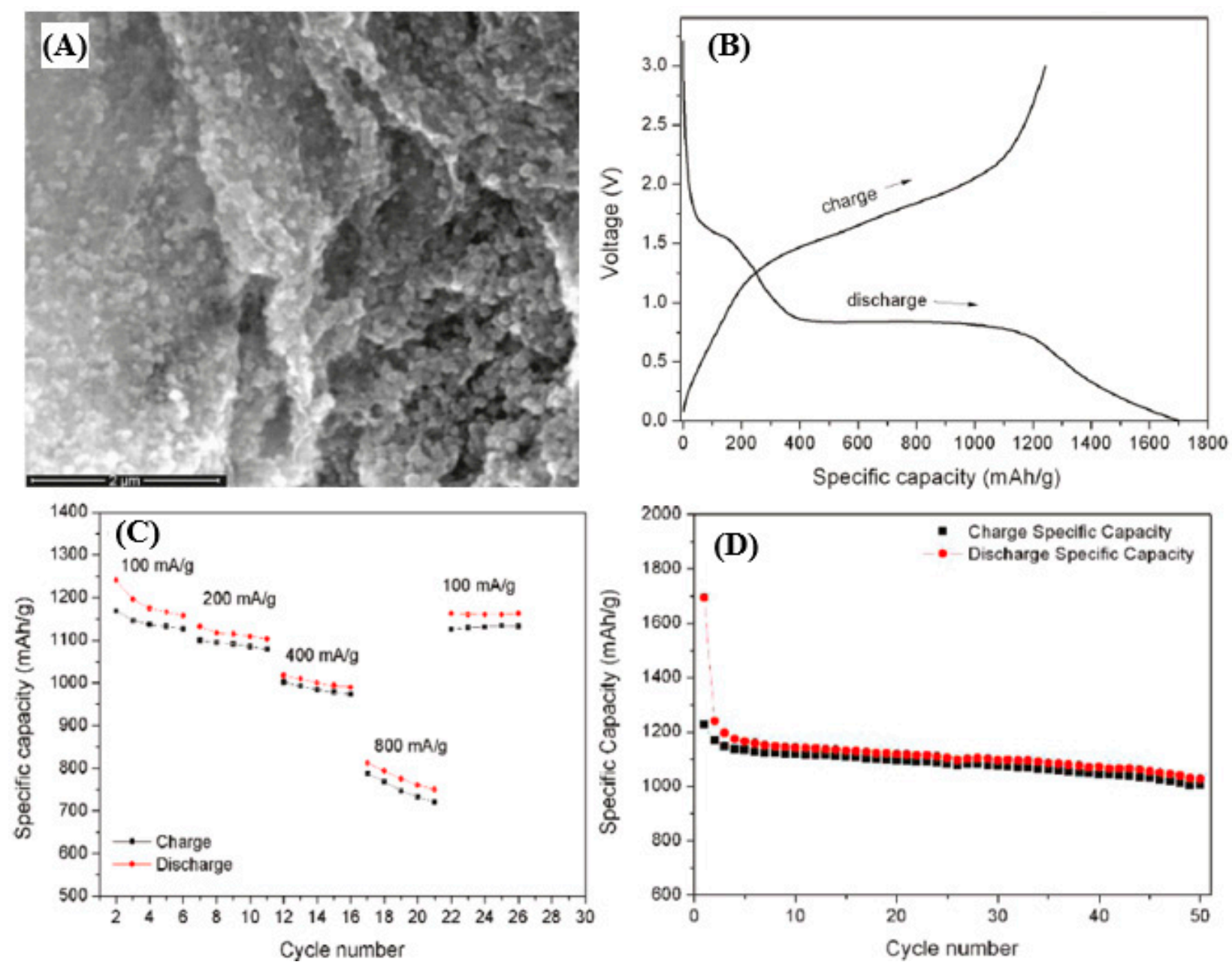

Figure 8. (A) SEM image of $\mathrm{rGO} / \mathrm{Fe}_{2} \mathrm{O}_{3}$ composites. (B) First discharge/charge profiles of $\mathrm{rGO} / \mathrm{Fe}_{2} \mathrm{O}_{3}$ composites for the first cycle at the current density of $100 \mathrm{~mA} / \mathrm{g}$. (C) Rate capacity of $\mathrm{rGO} / \mathrm{Fe}_{2} \mathrm{O}_{3}$ composites between 0.05 and $3.0 \mathrm{~V}$ with different current densities. (D) Cycling performance of $\mathrm{rGO} / \mathrm{Fe}_{2} \mathrm{O}_{3}$ composites at the current density of $100 \mathrm{~mA} / \mathrm{g}$. All the specific capacities are based on the mass of $\mathrm{Fe}_{2} \mathrm{O}_{3}$. Reproduced from [129] with permission from the American Chemical Society, 2011. 


\section{MCNs for Fuel Cells}

A third important application for MCNs is for the oxygen reduction reaction (ORR) in the fuel cells to replace the Pt-based catalysts, which are costly and have limited availability and poor durability [130]. Both experimental and theoretical studies show the possibility of making $\mathrm{p}$ - and n-type semiconductors by substituting $\mathrm{C}$ atoms with $\mathrm{B}$ and $\mathrm{N}$ atoms in the carbon frameworks in graphene and CNTs. The doped atoms are capable of modifying the electronic band structure of the carbon nanostructures, and consequently tuning the mechanical properties and electrocatalytic activity.

For example, Sheng et al. [131] reported a facile and catalyst-free approach to synthesize boron doped graphene (BG) by thermal annealing $\mathrm{GO}$ in the presence of $\mathrm{B}_{2} \mathrm{O}_{3}$. The electrocatalytic performance was evaluated in a three-electrode setup using $\mathrm{BG}$ or a pristine graphene-modified glassy carbon electrode (denoted as BG/GCE and graphene/GCE, respectively) in an $\mathrm{O}_{2}$-saturated $0.1 \mathrm{M} \mathrm{KOH}$ aqueous solution. Figure 9a shows the TEM image of BG, where the flattened BG nanosheets are randomly stacked together with a flake-like structure similar to that of the pristine graphene. Figure $9 \mathrm{~b}$ shows the linear sweep voltammetric curves (LSVs) of ORR at graphene/GCE, BG/GCE, and a bulk Pt disk electrode at a scan rate of $10 \mathrm{mV} \cdot \mathrm{s}^{-1}$. The onset potentials for ORR at pristine graphene are at $\sim 0.15$ and $\sim 0.59 \mathrm{~V}$, respectively. This indicates that the ORR process catalyzed by the pristine graphene is a two-step, two-electron pathway with the formation of intermediate $\mathrm{HO}_{2}{ }^{-}$ions. In contrast, the $\mathrm{BG} / \mathrm{GCE}$, in the case of the Pt electrode, exhibits a one-step process for ORR with the onset potential at about $-0.05 \mathrm{~V}$, which is about $100 \mathrm{mV}$ more positive than that on the pristine graphene/GCE. The one-step process suggests a four-electron pathway for the ORR at BG. Both the positive shift of the onset potential and the enhanced reduction current for ORR on BG/GCE demonstrate that BG possesses much higher electrocatalytic activity towards ORR than graphene, which could be explained by the faster reaction kinetics with a higher transferred electron number per oxygen molecule at the former (Figure 9c). The average electron transfer number $n$ for ORR at BG/GCE is calculated as 3.5 over the potential range from -0.4 to $-0.9 \mathrm{~V}$, which is much higher than that of the pristine graphene (2.1-2.7), indicating that the N-doped carbon materials demonstrate much better electrocatalytic activity towards ORR than pristine carbon. The BG catalyst shows considerable stability during ORR after 5000 cycles (Figure 9d), indicating an excellent electrocatalytic performance of BG after the incorporation of $\mathrm{B}$ atoms into graphene. Recently, researchers have also found that graphene doped with elements that have similar electronegativities to carbon, such as sulfur and selenium, can also exhibit better catalytic activity than commercial $\mathrm{Pt} / \mathrm{C}$ catalyst in alkaline media [132]. This study gives further insight into the ORR mechanism of these metal-free doped carbon materials, but also opens ways to fabricate other new lowcost non-precious-metal catalysts. However, these doped carbon materials usually exhibit ORR activity in alkaline electrolytes but poor activity in acids. 

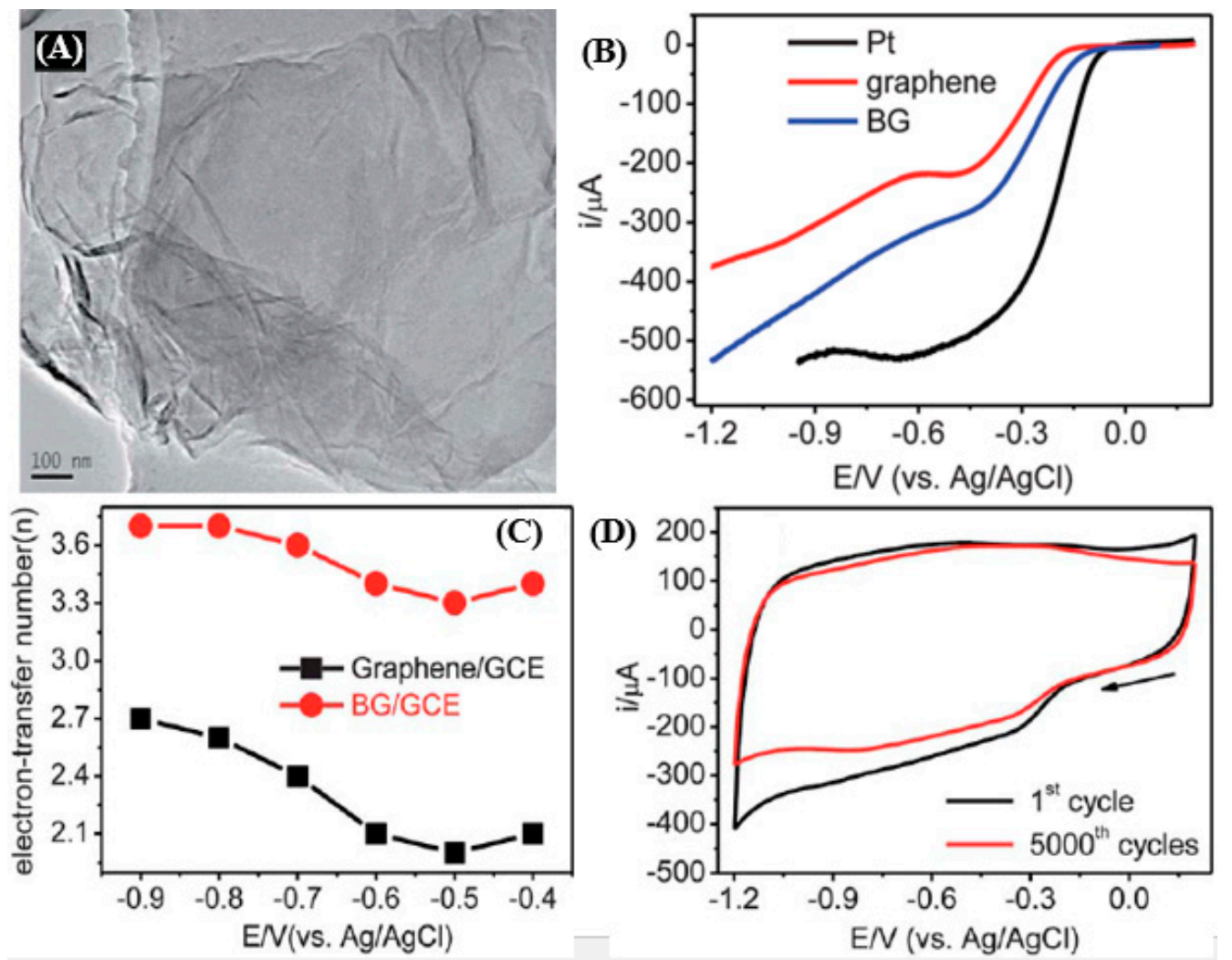

Figure 9. (A) TEM image of boron-doped graphene (BG). (B) Liner sweep voltammetric curves (LSVs) of ORR for graphene/GCE (red), BG/GCE (blue) and bulk Pt disk electrode (black) in an $\mathrm{O}_{2}$-saturated $0.1 \mathrm{M} \mathrm{KOH}$ aqueous solution (scan rate: $10 \mathrm{mV} \cdot \mathrm{s}-1$ ). The rotation rate of RDE was $1200 \mathrm{rpm}$. (C) The dependence of $\mathrm{n}$ on potential for the BG/GCE and pure graphene/GCE. (D) CVs of BG/GCE for ORR in $\mathrm{O}_{2}$-saturated $0.1 \mathrm{M} \mathrm{KOH}$ aqueous solution. The first scan (black) and the 5000th scan (red). Scan rate: $100 \mathrm{mV} \cdot \mathrm{s}^{-1}$. Reproduced from [131] with permission from the Royal Society of Chemistry, 2012.

To address this problem, Li et al. [133] fabricated few-walled carbon nanotube-graphene (NT-G) complexes, which show ORR activities in both acidic and alkaline solutions. Figure 10a presents high-resolution aberration-corrected transmission electron microscopy (TEM) images of the NT-G material. The nanotubes are mostly two- to three- walled, with their outer walls damaged and exfoliated to form single-layered nanosized graphene pieces $(\sim 5 \mathrm{~nm})$ or ribbon-like structures by the harsh oxidation process. These graphene structures exhibit abundant edges and are often found attached to the nanotubes. Regions with intact inner walls on the exfoliated nanotubes are also frequently observed. Figure 10b,c depicts the comparisons of ORR catalytic activity on $20 \mathrm{wt} \% \mathrm{Pt}$ on Vulcan carbon black (Pt/C from E-tek) and NT-G in acidic and basic media, respectively. The catalyst shows markedly higher ORR catalytic activity than previous CNT-based electrocatalysts in the acidic medium of $0.1-\mathrm{M} \mathrm{HClO}_{4}$. In 0.1-M KOH electrolyte, the NT-G catalyst shows an ORR activity closely approaching that of the $\mathrm{Pt} / \mathrm{C}$. Figure 10d,e show the rotating ring disk electrode (RRDE) polarization curves measured in the presence of $0.5-\mathrm{M}$ methanol. A drastic decrease in the ORR activity of $\mathrm{Pt} / \mathrm{C}$ is observed. In contrast, the NT-G catalyst shows little activity loss, exhibiting excellent tolerance to methanol poisoning. Figure $10 \mathrm{f}$ shows the $\mathrm{CV}$ curves of NT-before and after purification of iron. The purification and iron removal 
steps cause a large loss in ORR activity in the purified NT-G, with an onset-ORR potential $\sim 100 \mathrm{mV}$ more negative than NT-G, which indicates a positive role of the iron impurities. Similarly, the advantages of heteroatom doping in carbon structure and the expansion of functional groups have been demonstrated due to the increased active sites, which provide an inexpensive alternatives to preciousmetal electrocatalysts in fuel cells.
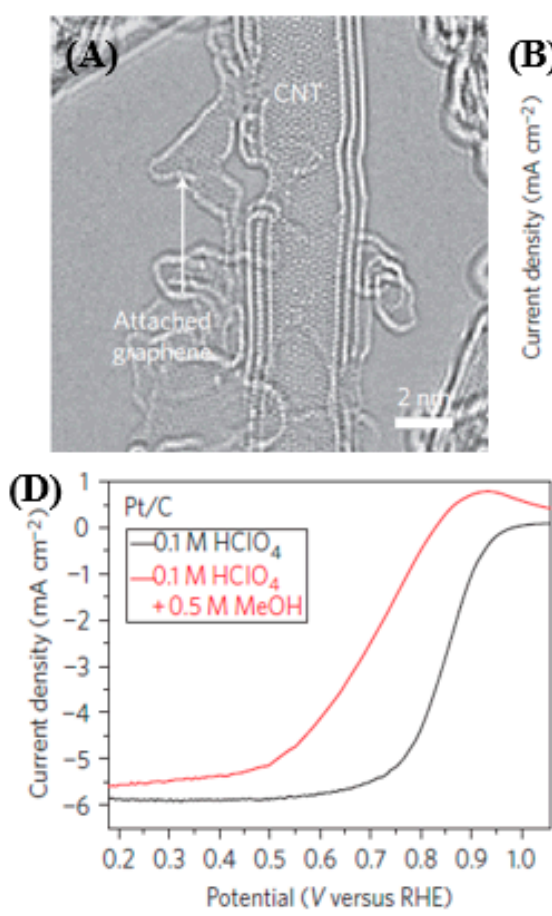
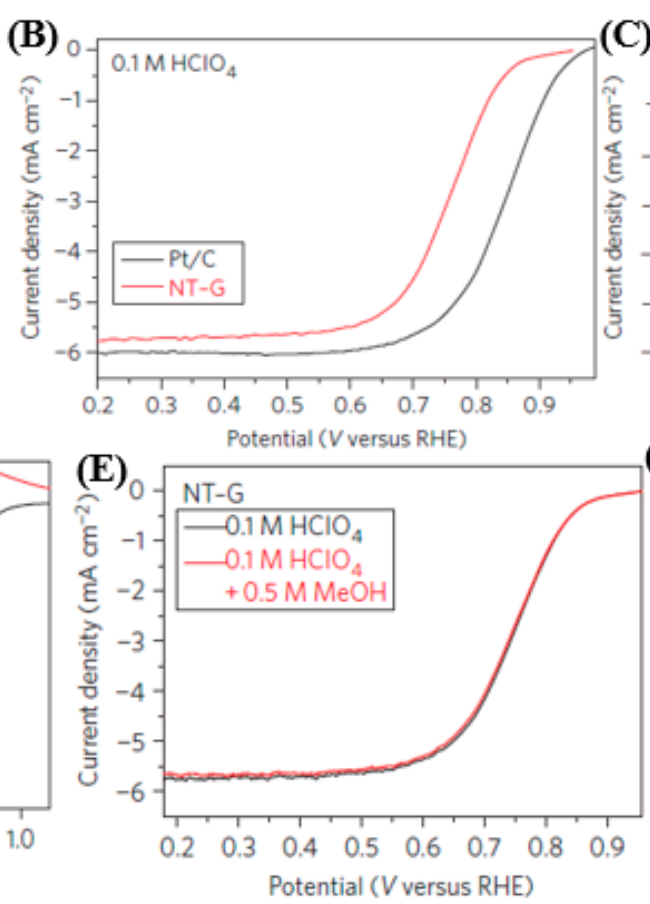

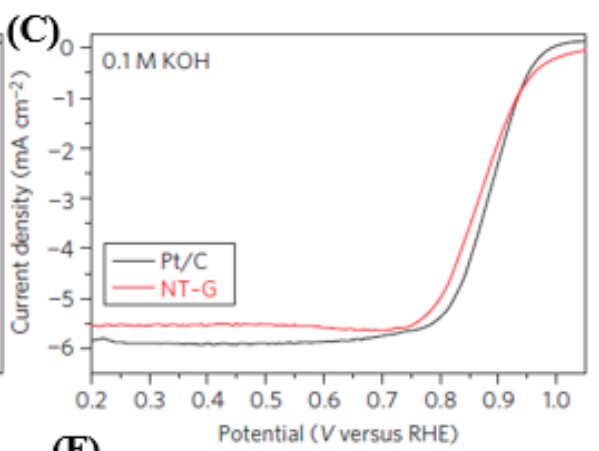

(F)

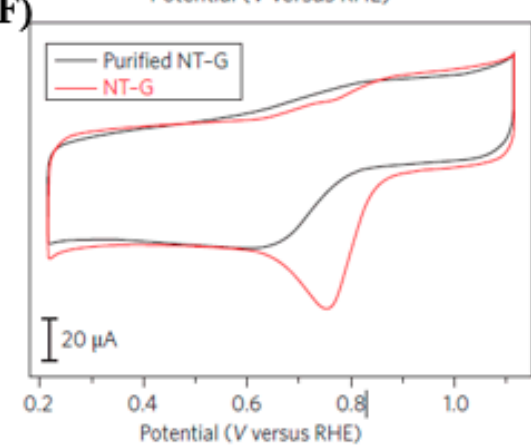

Figure 10. (A) Aberration-corrected TEM images of the NT-G (carbon nanotube-graphene complex) material, showing damaged outer walls and exfoliated graphene pieces attached to double- or triple-walled carbon nanotubes (CNTs). RRDE polarization curves of $20 \% \mathrm{Pt} / \mathrm{C}$ (black) and NT-G (red) in (B) $\mathrm{O}_{2}$-saturated $0.1 \mathrm{M} \mathrm{HClO} 4$ and (C) $\mathrm{O}_{2}$-saturated $0.1 \mathrm{M} \mathrm{KOH}$, respectively. (D,E) RRDE polarization curves of the NT-G catalyst before and after 8000 potential cycles in argon- or $\mathrm{O}_{2}$-saturated $0.1 \mathrm{M} \mathrm{HClO}_{4}$, respectively. Potential cycling was carried out between 0.6 and $1.0 \mathrm{~V}$ versus $\mathrm{RHE}$ at $50 \mathrm{mV} / \mathrm{s}$. (F) Comparison of the RRDE polarization curves of NT-G with/without intentional iron impurity removal. Reproduced from [133] with permission from Nature Publishing Group, 2012.

\section{Conclusions and Perspectives}

This review gives the most recent developments in the field of energy storage devices - specifically, electrochemical capacitors, lithium ion batteries, and fuel cells - utilizing MCNs. On the nanoscale, the physical and chemical behaviors of such MCNs are strongly influenced by their structure and interfacial interactions with their surrounding bulk materials or other nanomaterials. The advanced design and testing of these MCNs for energy storage devices are emphasized with comprehensive examples. There are still some shortcomings and disadvantages related to different carbon nanostructures, such as the irreversible capacity loss, big voltage crosstalk, low density, and so on. Novel composites containing multifunctional nanostructured-carbon and other dopants can synergistically take advantage of the 
combination of ordered building block units with other desired properties. It is possible to expect a breakthrough improvement of the performance of electrical storage devices if we keep moving forward in this systematic manner accompanied with fundamental understanding of theory and in situ experimentation.

\section{Acknowledgments}

This work is supported by the National Science Foundation (NSF CBET 11-37441, CMMI 13-14486).

\section{Author Contributions}

Yiran Wang, Huige Wei, and Yang Lu each provided extensive literature searches and all contributed to the writing of the review, under the supervision of Professors Wei, Wujcik, and Guo.

\section{Conflicts of Interest}

The authors declare no conflict of interest.

\section{References}

1. Simon, P.; Gogotsi, Y. Materials for electrochemical capacitors. Nat. Mater. 2008, 7, 845-854.

2. Wang, G.; Zhang, L.; Zhang, J. A review of electrode materials for electrochemical supercapacitors. Chem. Soc. Rev. 2012, 41, 797-828.

3. Díaz-González, F.; Sumper, A.; Gomis-Bellmunt, O.; Villafáfila-Robles, R. A review of energy storage technologies for wind power applications. Renew. Sustain. Energy Rev. 2012, 16, 2154-2171.

4. Cook, T.R.; Dogutan, D.K.; Reece, S.Y.; Surendranath, Y.; Teets, T.S.; Nocera, D.G. Solar energy supply and storage for the legacy and nonlegacy worlds. Chem. Rev. 2010, 110, 6474-6502.

5. Ibrahim, H.; Ilinca, A.; Perron, J. Energy storage systems-Characteristics and comparisons. Renew. Sustain. Energy Rev. 2008, 12, 1221-1250.

6. Manthiram, A.; Vadivel Murugan, A.; Sarkar, A.; Muraliganth, T. Nanostructured electrode materials for electrochemical energy storage and conversion. Energy Environ. Sci. 2008, 1, 621-638.

7. Béguin, F.; Frackowiak, E. (Eds.) Carbons for Electrochemical Energy Storage and Conversion Systems; CRC Press: Boca Raton, FL, USA, 2010.

8. Shen, J.; Liu, A.; Tu, Y.; Foo, G.; Yeo, C.; Chan-Park, M.B.; Jiang, R.; Chen, Y. How carboxylic groups improve the performance of single-walled carbon nanotube electrochemical capacitors? Energy Environ. Sci. 2011, 4, 4220-4229.

9. Wei, H.; Gu, H.; Guo, J.; Wei, S.; Guo, Z. Multiwalled carbon nanotubes with tuned surface functionalities for electrochemical energy storage. ECS J. Solid State Sci. Technol. 2013, 2, M3008-M3014.

10. Ding, K.; Wang, Y.; Yang, H.; Zheng, C.; Cao, Y.; Wei, H.; Wang, Y.; Guo, Z. Electrocatalytic activity of multi-walled carbon nanotubes-supported PtxPdy catalysts prepared by a pyrolysis process toward ethanol oxidation reaction. Electrochim. Acta 2013, 100, 147-156. 
11. Ding, K.; Li, Y.; Zhao, Y.; Liu, L.; Gu, H.; Liu, L.; Qiu, S.; He, C.; Liu, J.; Wang, Q.; et al. Dry-grinding Synthesized multi-walled carbon nanotubes supported PdO catalyst for ethanol oxidation reaction. Electrochim. Acta 2014, 149, 186-192.

12. Kroto, H.W.; Heath, J.R.; O’Brien, S.C.; Curl, R.F.; Smalley, R.E. C60: Buckminsterfullerene. Nature 1985, 318, 162-163.

13. Krätschmer, W.; Lamb, L.D.; Fostiropoulos, K.; Huffman, D.R. Solid C60: A new form of carbon. Nature 1990, 347, 354-358.

14. Diederich, F.; Thilgen, C. Covalent fullerene chemistry. Science 1996, 271, 317-324.

15. Iijima, S. Helical microtubules of graphitic carbon. Nature 1991, 354, 56-58.

16. Thess, A.; Lee, R.; Nikolaev, P.; Dai, H.; Petit, P.; Robert, J.; Xu, C.; Lee, Y.H.; Kim, S.G.; Rinzler, A.G.; et al. Crystalline ropes of metallic carbon nanotubes. Science 1996, 273, 483-487.

17. Ebbesen, T.W.; Ajayan, P.M. Large-scale synthesis of carbon nanotubes. Nature 1992, 358, $220-222$.

18. Wei, B.Q.; Vajtai, R.; Jung, Y.; Ward, J.; Zhang, R.; Ramanath, G.; Ajayan, P.M. Microfabrication technology: Organized assembly of carbon nanotubes. Nature 2002, 416, 495-496.

19. Yan, Y.; Chan-Park, M.B.; Zhang, Q. Advances in carbon-nanotube assembly. Small 2007, 3, $24-42$.

20. Novoselov, K.S.; Geim, A.K.; Morozov, S.V.; Jiang, D.; Zhang, Y.; Dubonos, S.V.; Grigorieva, I.V.; Firsov, A.A. Electric field effect in atomically thin carbon films. Science 2004, 306, 666-669.

21. Geim, A.K.; Novoselov, K.S. The rise of graphene. Nat. Mater. 2007, 6, 183-191.

22. Sutter, P. Epitaxial graphene: How silicon leaves the scene. Nat. Mater. 2009, 8, 171-172.

23. Novoselov, K.S.; Geim, A.K.; Morozov, S.V.; Jiang, D.; Katsnelson, M.I.; Grigorieva, I.V.; Dubonos, S.V.; Firsov, A.A. Two-dimensional gas of massless dirac fermions in graphene. Nature 2005, 438, 197-200.

24. Pletikosić, I.; Kralj, M.; Pervan, P.; Brako, R.; Coraux, J.; N’Diaye, A.; Busse, C.; Michely, T. Dirac cones and minigaps for Graphene on Ir (111). Phys. Rev. Lett. 2009, 102, 056808.

25. Hone, J.; Whitney, M.; Piskoti, C.; Zettl, A. Thermal conductivity of single-walled carbon nanotubes. Phys. Rev. B 1999, 59, R2514-R2516.

26. Berber, S.; Kwon, Y.K.; Tománek, D. Unusually high thermal conductivity of carbon nanotubes. Phys. Rev. Lett. 2000, 84, 4613-4616.

27. Jishi, R.; Dresselhaus, M.; Dresselhaus, G. Electron-phonon coupling and the electrical conductivity of fullerene nanotubules. Phys. Rev. B 1993, 48, 11385-11389.

28. Ebbesen, T.W.; Lezec, H.J.; Hiura, H.; Bennett, J.W.; Ghaemi, H.F.; Thio, T. Electrical conductivity of individual carbon nanotubes. Nature 1996, 382, 54-56.

29. Yao, Z.; Kane, C.; Dekker, C. High-Field electrical transport in single-wall carbon nanotubes. Phys. Rev. Lett. 2000, 84, 2941-2944.

30. Castro Neto, A.; Guinea, F.; Peres, N.; Novoselov, K.; Geim, A. The electronic properties of graphene. Rev. Mod. Phys. 2009, 81, 109-162.

31. Bunker, C.E.; Lawson, G.E.; Sun, Y.P. Fullerene-Styrene Random Copolymers. Novel Optical Properties. Macromolecules 1995, 28, 3744-3746.

32. Kataura, H.; Maniwa, Y.; Abe, M.; Fujiwara, A.; Kodama, T.; Kikuchi, K.; Imahori, H.; Misaki, Y.; Suzuki, S.; Achiba, Y. Optical properties of fullerene and non-fullerene peapods. Appl. Phys. A 2002, 74, 349-354. 
33. Bachilo, S.M.; Strano, M.S.; Kittrell, C.; Hauge, R.H.; Smalley, R.E.; Weisman, R.B. Structure-assigned optical spectra of single-walled carbon nanotubes. Science 2002, 298, 2361-2366.

34. Lee, C.; Wei, X.; Kysar, J.W.; Hone, J. Measurement of the elastic properties and intrinsic strength of monolayer graphene. Science 2008, 321, 385-388.

35. Peigney, A.; Laurent, C.; Flahaut, E.; Bacsa, R.R.; Rousset, A. Specific surface area of carbon nanotubes and bundles of carbon nanotubes. Carbon 2001, 39, 507-514.

36. Yang, Z.; Xia, Y.; Mokaya, R. Enhanced hydrogen storage capacity of high surface area zeolite-like carbon materials. J. Am. Chem. Soc. 2007, 129, 1673-1679.

37. Blasdel, N.J.; Wujcik, E.K.; Carletta, J.E.; Lee, K.S.; Monty, C.N. Fabric nanocomposite resistance temperature detector. IEEE Sens. J. 2015, 15, 300-306.

38. Yan, C.; Wang, J.; Kang, W.; Cui, M.; Wang, X.; Foo, C.Y.; Chee, K.J.; Lee, P.S. Highly stretchable piezoresistive graphene-nanocellulose nanopaper for strain sensors. Adv. Mater. 2014, 26, 2022-2027.

39. Lipomi, D.J.; Vosgueritchian, M.; Tee, B.C.K.; Hellstrom, S.L.; Lee, J.A.; Fox, C.H.; Bao, Z. Skinlike pressure and strain sensors based on transparent elastic films of carbon nanotubes. Nat. Nanotechnol. 2011, 6, 788-792.

40. Wujcik, E.K.; Wei, H.; Zhang, X.; Guo, J.; Yan, X.; Sutrave, N.; Wei, S.; Guo, Z. Antibody nanosensors: A detailed review. RSC Adv. 2014, 4, 43725-43745.

41. Monty, C.N.; Wujcik, E.K.; Blasdel, N.J. Flexible Electrode for Detecting Changes in Temperature, Humidity, and Sodium Ion Concentration in Sweat. U.S. Patent 20130197319A1, 28 January 2013.

42. Wujcik, E.K.; Monty, C.N. Nanotechnology for implantable sensors: Carbon nanotubes and graphene in medicine. Wiley Interdiscip. Rev. Nanomed. Nanobiotechnol. 2013, 5, 233-249.

43. Wujcik, E.K.; Blasdel, N.J.; Trowbridge, D.; Monty, C.N. Ion sensor for the quantification of sodium in sweat samples. IEEE Sens. J. 2013, 13, 3430-3436.

44. Wujcik, E.K. Discovery of Nanostructured Material Properties for Advanced Sensing Platforms. In Electronic Dissertation; The University of Akron: Akron, OH, USA, 2013.

45. Guo, C.X.; Yang, H.B.; Sheng, Z.M.; Lu, Z.S.; Song, Q.L.; Li, C.M. Layered graphene/quantum dots for photovoltaic devices. Angew. Chem. Int. Ed. 2010, 49, 3014-3017.

46. Wei, J.; Jia, Y.; Shu, Q.; Gu, Z.; Wang, K.; Zhuang, D.; Zhang, G.; Wang, Z.; Luo, J.; Cao, A.; Wu, D. Double-walled carbon nanotube solar cells. Nano Lett. 2007, 7, 2317-2321.

47. Ross, R.B.; Cardona, C.M.; Guldi, D.M.; Sankaranarayanan, S.G.; Reese, M.O.; Kopidakis, N.; Peet, J.; Walker, B.; Bazan, G.C.; Drees, M.; et al. Endohedral fullerenes for organic photovoltaic devices. Nat. Mater. 2009, 8, 208-212.

48. Javey, A.; Guo, J.; Wang, Q.; Lundstrom, M.; Dai, H. Ballistic carbon nanotube field-effect transistors. Nature 2003, 424, 654-657.

49. Wang, X.; Ouyang, Y.; Li, X.; Wang, H.; Guo, J.; Dai, H. Room-temperature all-semiconducting sub-10-nm graphene nanoribbon field-effect transistors. Phys. Rev. Lett. 2008, 100, 206803.

50. Xia, F.; Farmer, D.B.; Lin, Y.; Avouris, P. Graphene field-effect transistors with high on/off current ratio and large transport band gap at room temperature. Nano Lett. 2010, 10, 715-718. 
51. Li, W.; Liang, C.; Zhou, W.; Qiu, J.; Zhou, Z.; Sun, G.; Xin, Q. Preparation and characterization of multiwalled carbon nanotube-supported platinum for cathode catalysts of direct methanol fuel cells. J. Phys. Chem. B 2003, 107, 6292-6299.

52. Seger, B.; Kamat, P.V. Electrocatalytically active graphene-platinum nanocomposites. Role of 2-D carbon support in PEM fuel cells. J. Phys. Chem. C 2009, 113, 7990-7995.

53. Qie, L.; Chen, W.M.; Wang, Z.H.; Shao, Q.G.; Li, X.; Yuan, L.X.; Hu, X.L.; Zhang, W.X.; Huang, Y.H. Nitrogen-doped porous carbon nanofiber webs as anodes for lithium ion batteries with a superhigh capacity and rate capability. Adv. Mater. 2012, 24, 2047-2050.

54. Stoller, M.D.; Park, S.; Zhu, Y.; An, J.; Ruoff, R.S. Graphene-based ultracapacitors. Nano Lett. 2008, 8, 3498-3502.

55. Zhu, J.; Chen, M.; Qu, H.; Luo, Z.; Wu, S.; Colorado, H.A.; Wei, S.; Guo, Z. Magnetic field induced capacitance enhancement in graphene and magnetic graphene nanocomposites. Energy Environ. Sci. 2012, 6, 194-204.

56. Liu, C.; Yu, Z.; Neff, D.; Zhamu, A.; Jang, B.Z. Graphene-based supercapacitor with an ultrahigh energy density. Nano Lett. 2010, 10, 4863-4868.

57. Zhu, J.; Chen, M.; Wei, H.; Yerra, N.; Haldolaarachchige, N.; Luo, Z.; Young, D.P.; Ho, T.C.; Wei, S.; Guo, Z. Magnetocapacitance in magnetic microtubular carbon nanocomposites under external magnetic field. Nano Energy 2014, 6, 180-192.

58. Ajayan, P.M.; Stephan, O.; Colliex, C.; Trauth, D. Aligned carbon nanotube arrays formed by cutting a polymer resin-Nanotube composite. Science 1994, 265, 1212-1214.

59. Stankovich, S.; Dikin, D.A.; Dommett, G.H.B.; Kohlhaas, K.M.; Zimney, E.J.; Stach, E.A.; Piner, R.D.; Nguyen, S.T.; Ruoff, R.S. Graphene-based composite materials. Nature 2006, 442, 282-286.

60. Zhao, X.; Zhang, Q.; Chen, D.; Lu, P. Enhanced mechanical properties of graphene-based poly (vinyl alcohol) composites. Macromolecules 2010, 43, 2357-2363.

61. Wang, Y.; He, Q.; Qu, H.; Zhang, X.; Guo, J.; Zhu, J.; Zhao, G.; Colorado, H.A.; Yu, J.; Sun, L.; et al. Magnetic graphene oxide nanocomposites: Nanoparticles growth mechanism and property analysis. J. Mater. Chem. C 2014, 2, 9478-9488.

62. Liu, J.; Huang, J.; Wujcik, E.K.; Qiu, B.; Rutman, D.; Zhang, X.; Salazard, E.; Wei, S.; Guo, Z. Hydrophobic electrospun polyimide nanofibers for self-cleaning materials. Macromol. Mater. Eng. 2015, 300, 358-368.

63. Tang, Z.; Wu, H.; Cort, J.R.; Buchko, G.W.; Zhang, Y.; Shao, Y.; Aksay, I.A.; Liu, J.; Lin, Y. Constraint of DNA on functionalized graphene improves its biostability and specificity. Small 2010, 6, 1205-1209.

64. Harrison, B.S.; Atala, A. Carbon nanotube applications for tissue engineering. Biomaterials 2007, 28, 344-353.

65. Zhu, J.; Wei, S.; Gu, H.; Rapole, S.B.; Wang, Q.; Luo, Z.; Haldolaarachchige, N.; Young, D.P.; Guo, Z. One-pot synthesis of magnetic graphene nanocomposites decorated with core@double-shell nanoparticles for fast chromium removal. Environ. Sci. Technol. 2011, 46, 977-985.

66. Zhu, J.; Sadu, R.; Wei, S.; Chen, D.H.; Haldolaarachchige, N.; Luo, Z.; Gomes, J.A.; Young, D.P.; Guo, Z. Magnetic graphene nanoplatelet composites toward arsenic removal. ECS J. Solid State Sci. Technol. 2012, 1, M1-M5. 
67. Lota, G.; Fic, K.; Frackowiak, E. Carbon nanotubes and their composites in electrochemical applications. Energy Environ. Sci. 2011, 4, 1592.

68. Jiang, H.; Lee, P.S.; Li, C. 3D carbon based nanostructures for advanced supercapacitors. Energy Env. Sci. 2013, 6, 41-53.

69. Portet, C.; Yushin, G.; Gogotsi, Y. Electrochemical performance of carbon onions, nanodiamonds, carbon black and multiwalled nanotubes in electrical double layer capacitors. Carbon 2007, 45, 2511-2518.

70. Piner, R.; Li, H.; Kong, X.; Tao, L.; Kholmanov, I.N.; Ji, H.; Lee, W.H.; Suk, J.W.; Ye, J.; Hao, Y.; et al. Graphene synthesis via magnetic inductive heating of copper substrates. ACS Nano 2013, 7, 7495-7499.

71. Torres, J.A.; Kaner, R.B. Graphene synthesis: Graphene closer to fruition. Nat. Mater. 2014, 13, $328-329$.

72. Kimura, H.; Goto, J.; Yasuda, S.; Sakurai, S.; Yumura, M.; Futaba, D.N.; Hata, K. Unexpectedly high yield carbon nanotube synthesis from low-activity carbon feedstocks at high concentrations. ACS Nano 2013, 7, 3150-3157.

73. Jiang, C.; Saha, A.; Xiang, C.; Young, C.C.; Tour, J.M.; Pasquali, M.; Martí, A.A. Increased solubility, liquid-crystalline phase, and selective functionalization of single-walled carbon nanotube polyelectrolyte dispersions. ACS Nano 2013, 7, 4503-4510.

74. Song, S.H.; Park, K.H.; Kim, B.H.; Choi, Y.W.; Jun, G.H.; Lee, D.J.; Kong, B.S.; Paik, K.W.; Jeon, S. Enhanced Thermal conductivity of epoxy-graphene composites by using non-oxidized graphene flakes with non-covalent functionalization. Adv. Mater. 2013, 25, 732-737.

75. Chen, W.; Li, S.; Chen, C.; Yan, L. Self-assembly and embedding of nanoparticles by in situ reduced graphene for preparation of a 3D graphene/nanoparticle aerogel. Adv. Mater. 2011, 23, 5679-5683.

76. Palma, M.; Wang, W.; Penzo, E.; Brathwaite, J.; Zheng, M.; Hone, J.; Nuckolls, C.; Wind, S.J. Controlled formation of carbon nanotube junctions via linker-induced assembly in aqueous solution. J. Am. Chem. Soc. 2013, 135, 8440-8443.

77. Wang, H.; Xu, Z.; Yi, H.; Wei, H.; Guo, Z.; Wang, X. One-step preparation of single-crystalline $\mathrm{Fe}_{2} \mathrm{O}_{3}$ particles/graphene composite hydrogels as high performance anode materials for supercapacitors. Nano Energy 2014, 7, 86-96.

78. Yang, X.; Cheng, C.; Wang, Y.; Qiu, L.; Li, D. Liquid-mediated dense integration of graphene materials for compact capacitive energy storage. Science 2013, 341, 534-537.

79. Habisreutinger, S.N.; Leijtens, T.; Eperon, G.E.; Stranks, S.D.; Nicholas, R.J.; Snaith, H.J. Carbon nanotube/polymer composites as a highly stable hole collection layer in perovskite solar cells. Nano Lett. 2014, 14, 5561-5568.

80. Evanoff, K.; Khan, J.; Balandin, A.A.; Magasinski, A.; Ready, W.J.; Fuller, T.F.; Yushin, G. Towards ultrathick Battery Electrodes: Aligned carbon nanotube-Enabled architecture. Adv. Mater. 2012, 24, 533-537.

81. Geim, A.K. Graphene: Status and prospects. Science 2009, 324, 1530-1534.

82. Zhu, J.; Chen, M.; He, Q.; Shao, L.; Wei, S.; Guo, Z. An overview of the engineered graphene nanostructures and nanocomposites. RSC Adv. 2013, 3, 22790-22824. 
83. De Volder, M.F.L.; Tawfick, S.H.; Baughman, R.H.; Hart, A.J. Carbon nanotubes: Present and future commercial applications. Science 2013, 339, 535-539.

84. Jariwala, D.; Sangwan, V.K.; Lauhon, L.J.; Marks, T.J.; Hersam, M.C. Carbon nanomaterials for electronics, optoelectronics, photovoltaics, and sensing. Chem. Soc. Rev. 2013, 42, 2824-2860.

85. Dai, L.; Chang, D.W.; Baek, J.B.; Lu, W. Carbon nanomaterials for advanced energy conversion and storage. Small 2012, 8, 1130-1166.

86. Hall, P.J.; Mirzaeian, M.; Fletcher, S.I.; Sillars, F.B.; Rennie, A.J.R.; Shitta-Bey, G.O.; Wilson, G.; Cruden, A.; Carter, R. Energy storage in electrochemical capacitors: Designing functional materials to improve performance. Energy Environ. Sci. 2010, 3, 1238-1251.

87. Yu, G.; Xie, X.; Pan, L.; Bao, Z.; Cui, Y. Hybrid nanostructured materials for high-performance electrochemical capacitors. Nano Energy 2013, 2, 213-234.

88. Inagaki, M.; Konno, H.; Tanaike, O. Carbon materials for electrochemical capacitors. J. Power Sources 2010, 195, 7880-7903.

89. Sharma, P.; Bhatti, T.S. A review on electrochemical double-layer capacitors. Energy Convers. Manag. 2010, 51, 2901-2912.

90. Boota, M.; Hatzell, K.B.; Beidaghi, M.; Dennison, C.R.; Kumbur, E.C.; Gogotsi, Y. Activated carbon spheres as a flowable electrode in electrochemical flow capacitors. J. Electrochem. Soc. 2014, 161, A1078-A1083.

91. Ghosh, A.; Lee, Y.H. Carbon-based electrochemical capacitors. ChemSusChem 2012, 5, 480-499.

92. Zhang, C.; Hatzell, K.B.; Boota, M.; Dyatkin, B.; Beidaghi, M.; Long, D.; Qiao, W.; Kumbur, E.C.; Gogotsi, Y. Highly porous carbon spheres for electrochemical capacitors and capacitive flowable suspension electrodes. Carbon 2014, 77, 155-164.

93. Zhi, M.; Xiang, C.; Li, J.; Li, M.; Wu, N. Nanostructured carbon-metal oxide composite electrodes for supercapacitors: A review. Nanoscale 2013, 5, 72-88.

94. Hantel, M.M.; Kaspar, T.; Nesper, R.; Wokaun, A.; Kötz, R. Partially reduced graphite oxide for supercapacitor electrodes: Effect of graphene layer spacing and huge specific capacitance. Electrochem. Commun. 2011, 13, 90-92.

95. Zhang, L.L.; Zhao, X.; Stoller, M.D.; Zhu, Y.; Ji, H.; Murali, S.; Wu, Y.; Perales, S.; Clevenger, B.; Ruoff, R.S. Highly conductive and porous activated reduced graphene oxide films for high-power supercapacitors. Nano Lett. 2012, 12, 1806-1812.

96. Huang, Y.; Liang, J.; Chen, Y. An overview of the applications of graphene-based materials in supercapacitors. Small 2012, 8, 1805-1834.

97. Cheng, Q.; Tang, J.; Ma, J.; Zhang, H.; Shinya, N.; Qin, L.C. Graphene and carbon nanotube composite electrodes for supercapacitors with ultra-high energy density. Phys. Chem. Chem. Phys. 2011, 13, 17615-17624.

98. Fan, Z.; Yan, J.; Zhi, L.; Zhang, Q.; Wei, T.; Feng, J.; Zhang, M.; Qian, W.; Wei, F. A three-dimensional carbon nanotube/graphene sandwich and its application as electrode in supercapacitors. Adv. Mater. 2010, 22, 3723-3728.

99. Yang, S.Y.; Chang, K.H.; Tien, H.W.; Lee, Y.F.; Li, S.M.; Wang, Y.S.; Wang, J.Y.; Ma, C.C.M.; $\mathrm{Hu}$, C.C. Design and tailoring of a hierarchical graphene-carbon nanotube architecture for supercapacitors. J. Mater. Chem. 2011, 21, 2374-2380. 
100. Han, J.; Zhang, L.L.; Lee, S.; Oh, J.; Lee, K.S.; Potts, J.R.; Ji, J.; Zhao, X.; Ruoff, R.S.; Park, S. Generation of b-doped graphene nanoplatelets using a solution process and their supercapacitor applications. ACS Nano 2013, 7, 19-26.

101. Chen, P.; Yang, J.J.; Li, S.S.; Wang, Z.; Xiao, T.Y.; Qian, Y.H.; Yu, S.H. Hydrothermal synthesis of macroscopic nitrogen-doped graphene hydrogels for ultrafast supercapacitor. Nano Energy 2013, 2, 249-256.

102. Wen, Z.; Wang, X.; Mao, S.; Bo, Z.; Kim, H.; Cui, S.; Lu, G.; Feng, X.; Chen, J. Crumpled nitrogen-doped graphene nanosheets with ultrahigh pore volume for high-performance supercapacitor. Adv. Mater. 2012, 24, 5610-5616.

103. Chen, L.F.; Zhang, X.D.; Liang, H.W.; Kong, M.; Guan, Q.F.; Chen, P.; Wu, Z.Y.; Yu, S.H. Synthesis of nitrogen-doped porous carbon nanofibers as an efficient electrode material for supercapacitors. ACS Nano 2012, 6, 7092-7102.

104. Hou, Y.; Cheng, Y.; Hobson, T.; Liu, J. Design and synthesis of hierarchical $\mathrm{MnO}_{2}$ nanospheres/carbon nanotubes/conducting polymer ternary composite for high performance electrochemical electrodes. Nano Lett. 2010, 10, 2727-2733.

105. Wei, H.; Zhu, J.; Wu, S.; Wei, S.; Guo, Z. Electrochromic polyaniline/graphite oxide nanocomposites with endured electrochemical energy storage. Polymer 2013, 54, 1820-1831.

106. Wei, H.; Gu, H.; Guo, J.; Wei, S.; Guo, Z. Electropolymerized polyaniline nanocomposites from multi-walled carbon nanotubes with tuned surface functionalities for electrochemical energy storage. J. Electrochem. Soc. 2013, 160, G3038-G3045.

107. Wei, H.; Yan, X.; Wu, S.; Luo, Z.; Wei, S.; Guo, Z. Electropolymerized polyaniline stabilized tungsten oxide nanocomposite films: Electrochromic behavior and electrochemical energy storage. J. Phys. Chem. C 2012, 116, 25052-25064.

108. Wei, H.; Gu, H.; Guo, J.; Wei, S.; Liu, J.; Guo, Z. Silica doped nanopolyaniline with endured electrochemical energy storage and the magnetic field effects. J. Phys. Chem. C 2013, 117, 13000-13010.

109. Wei, H.; Wang, Y.; Guo, J.; Yan, X.; O’Connor, R.; Zhang, X.; Shen, N.Z.; Weeks, B.L.; Huang, X.; Wei, S.; et al. Electropolymerized polypyrrole nanocoatings on carbon paper for electrochemical energy storage. ChemElectroChem 2015, 2, 119-126.

110. Lu, X.; Dou, H.; Yuan, C.; Yang, S.; Hao, L.; Zhang, F.; Shen, L.; Zhang, L.; Zhang, X. Polypyrrole/carbon nanotube nanocomposite enhanced the electrochemical capacitance of flexible graphene film for supercapacitors. J. Power Sources 2012, 197, 319-324.

111. D’Arcy, J.M.; El-Kady, M.F.; Khine, P.P.; Zhang, L.; Lee, S.H.; Davis, N.R.; Liu, D.S.; Yeung, M.T.; Kim, S.Y.; Turner, C.L.; et al. Vapor-Phase polymerization of nanofibrillar poly (3,4-ethylenedioxythiophene) for supercapacitors. ACS Nano 2014, 8, 1500-1510.

112. Cheng, Q.; Tang, J.; Ma, J.; Zhang, H.; Shinya, N.; Qin, L.C. Graphene and nanostructured MnO2 composite electrodes for supercapacitors. Carbon 2011, 49, 2917-2925.

113. Jiang, H.; Ma, J.; Li, C. Mesoporous carbon incorporated metal oxide nanomaterials as supercapacitor electrodes. Adv. Mater. 2012, 24, 4197-4202.

114. Yu, G.; Hu, L.; Liu, N.; Wang, H.; Vosgueritchian, M.; Yang, Y.; Cui, Y.; Bao, Z. Enhancing the supercapacitor performance of graphene/MnO2 nanostructured electrodes by conductive wrapping. Nano Lett. 2011, 11, 4438-4442. 
115. De las Casas, C.; Li, W. A review of application of carbon nanotubes for lithium ion battery anode material. J. Power Sources 2012, 208, 74-85.

116. Cao, H.; Wang, X.; Gu, H.; Liu, J.; Luan, L.; Liu, W.; Wang, Y.; Guo, Z. Carbon coated manganese monoxide octahedron negative-electrode for lithium-ion batteries with enhanced performance. RSC Adv. 2015, 5, 34566-34571.

117. Li, X.; Gu, H.; Liu, J.; Wei, H.; Qiu, S.; Fu, Y.; Lv, H.; Lu, G.; Wang, Y.; Guo, Z. Multi-walled carbon nanotubes composited with nanomagnetite for anodes in lithium ion batteries. RSC Adv. 2014, 5, 7237-7244.

118. Hu, C.; Guo, S.; Lu, G.; Fu, Y.; Liu, J.; Wei, H.; Yan, X.; Wang, Y.; Guo, Z. Carbon coating and $\mathrm{Zn}^{2+}$ doping of magnetite nanorods for enhanced electrochemical energy storage. Electrochim. Acta 2014, 148, 118-126.

119. Gnana Kumar, G.; Reddy, K.; Nahm, K.S.; Angulakshmi, N.; Manuel Stephan, A. Synthesis and electrochemical properties of $\mathrm{SnS}$ as possible anode material for lithium batteries. J. Phys. Chem. Solids 2012, 73, 1187-1190.

120. Ge, M.; Rong, J.; Fang, X.; Zhou, C. Porous doped silicon nanowires for lithium ion battery anode with long cycle life. Nano Lett. 2012, 12, 2318-2323.

121. Reddy, A.L.M.; Srivastava, A.; Gowda, S.R.; Gullapalli, H.; Dubey, M.; Ajayan, P.M. Synthesis of nitrogen-doped graphene films for lithium battery application. ACS Nano 2010, 4, 6337-6342.

122. Guo, S.; Lu, G.; Qiu, S.; Liu, J.; Wang, X.; He, C.; Wei, H.; Yan, X.; Guo, Z. Carbon-coated MnO microparticulate porous nanocomposites serving as anode materials with enhanced electrochemical performances. Nano Energy 2014, 9, 41-49.

123. Zhou, G.; Wang, D.W.; Li, F.; Zhang, L.; Li, N.; Wu, Z.S. Graphene-wrapped Fe3O4 anode material with improved reversible capacity and cyclic stability for lithium ion batteries. Chem. Mater. 2010, 22, 5306-5313.

124. Wang, Z.; Zhou, L.; David Lou, X.W. Metal oxide hollow nanostructures for lithium-ion batteries. Adv. Mater. 2012, 24, 1903-1911.

125. Jiang, J.; Li, Y.; Liu, J.; Huang, X.; Yuan, C.; Lou, X.W. Recent advances in metal oxide-based electrode architecture design for electrochemical energy storage. Adv. Mater. 2012, 24, 5166-5180.

126. Wu, Z.S.; Ren, W.; Xu, L.; Li, F.; Cheng, H.M. Doped graphene sheets as anode materials with superhigh rate and large capacity for lithium ion batteries. ACS Nano 2011, 5, 5463-5471.

127. Yang, Z.; Shen, J.; Archer, L.A. An in situ method of creating metal oxide-carbon composites and their application as anode materials for lithium-ion batteries. J. Mater. Chem. 2011, 21, 11092-11097.

128. Li, H.; Zhou, H. Enhancing the performances of Li-ion batteries by carbon-coating: Present and future. Chem. Commun. 2012, 48, 1201-1217.

129. Zhu, X.; Zhu, Y.; Murali, S.; Stoller, M.D.; Ruoff, R.S. Nanostructured reduced graphene oxide/Fe2O3 composite as a high-performance anode material for lithium ion batteries. ACS Nano 2011, 5, 3333-3338.

130. Liu, L.; Wang, J.; Wei, H.; Guo, Z.; Ding, K. Using multi-walled carbon nanotubes as the reducing reagents to prepare ptxsny composite nanoparticles by a pyrolysis method for ethanol oxidation reaction. Int. J. Electrochem. Sci. 2014, 9, 2221-2236.

131. Sheng, Z.H.; Gao, H. L.; Bao, W.J.; Wang, F.B.; Xia, X.H. Synthesis of boron doped graphene for oxygen reduction reaction in fuel cells. J. Mater. Chem. 2012, 22, 390-395. 
132. Yang, Z.; Yao, Z.; Li, G.; Fang, G.; Nie, H.; Liu, Z.; Zhou, X.; Chen, X.; Huang, S. Sulfur-doped graphene as an efficient metal-free cathode catalyst for oxygen reduction. ACS Nano 2012, 6 , $205-211$.

133. Li, Y.; Zhou, W.; Wang, H.; Xie, L.; Liang, Y.; Wei, F.; Idrobo, J.-C.; Pennycook, S.J.; Dai, H. An oxygen reduction electrocatalyst based on carbon nanotube-graphene complexes. Nat. Nanotechnol. 2012, 7, 394-400.

(C) 2015 by the authors; licensee MDPI, Basel, Switzerland. This article is an open access article distributed under the terms and conditions of the Creative Commons Attribution license (http://creativecommons.org/licenses/by/4.0/). 